\title{
Discovery of nanomolar dengue and West Nile virus protease inhibitors containing a 4-benzyloxyphenylglycine residue
}

Mira A. M. Behnam, ${ }^{\dagger}$ Dominik Graf, ${ }^{\dagger}$ Ralf Bartenschlager, ${ }^{\S}$ Darius P. Zlotos, ${ }^{\dagger}$ and Christian D. Klein ${ }^{*} \dagger$

${ }^{\dagger}$ Medicinal Chemistry, Institute of Pharmacy and Molecular Biotechnology IPMB, Heidelberg University, Im Neuenheimer Feld 364, 69120 Heidelberg, Germany

${ }^{\S}$ Department of Infectious Diseases, Molecular Virology, and German Center for Infection Research, Heidelberg University, Im Neuenheimer Feld 345, 69120 Heidelberg, Germany

Department of Pharmaceutical Chemistry, The German University in Cairo, New Cairo City, 11835 Cairo, Egypt 


\section{$\underline{\text { Table of Contents }}$}

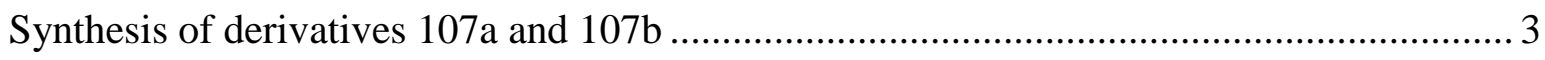

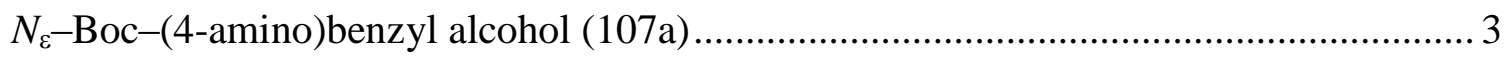

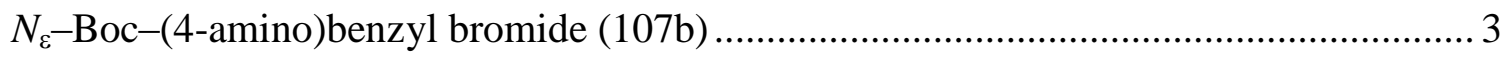

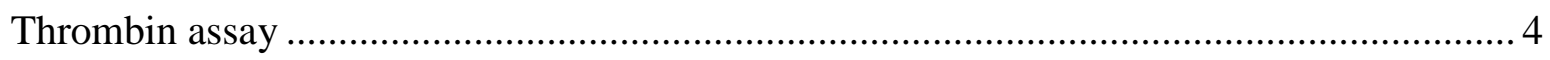

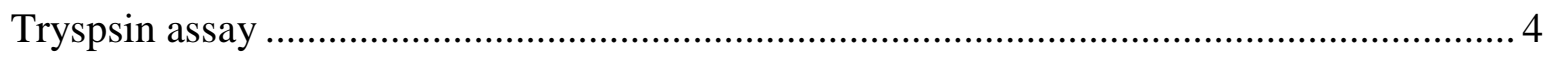

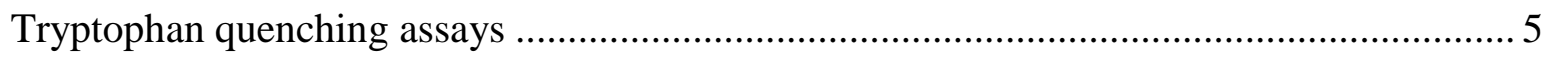

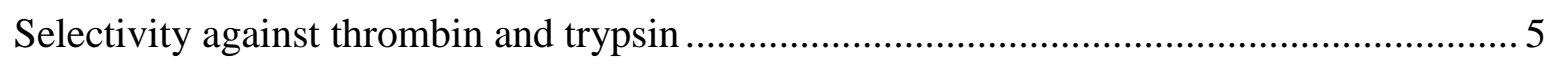

Binding mode analysis by tryptophan quenching assays .............................................. 8

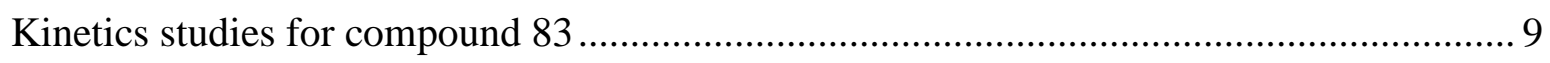

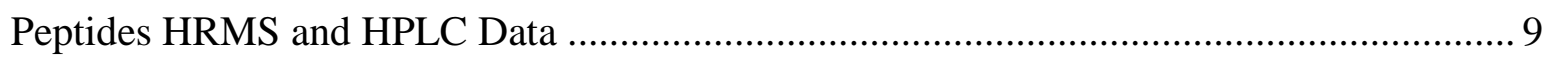

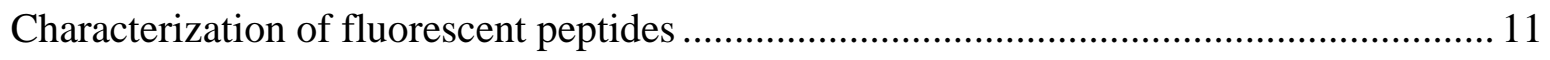

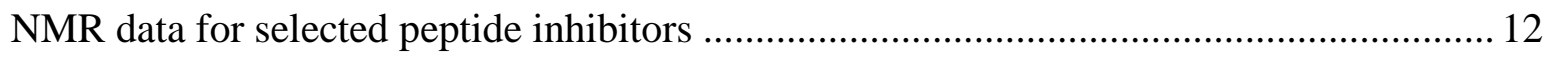

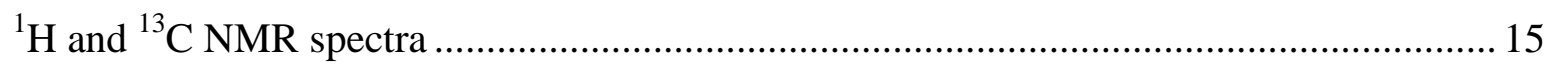

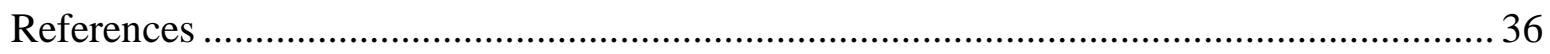




\section{Synthesis of derivatives $107 \mathrm{a}$ and $107 \mathrm{~b}$}

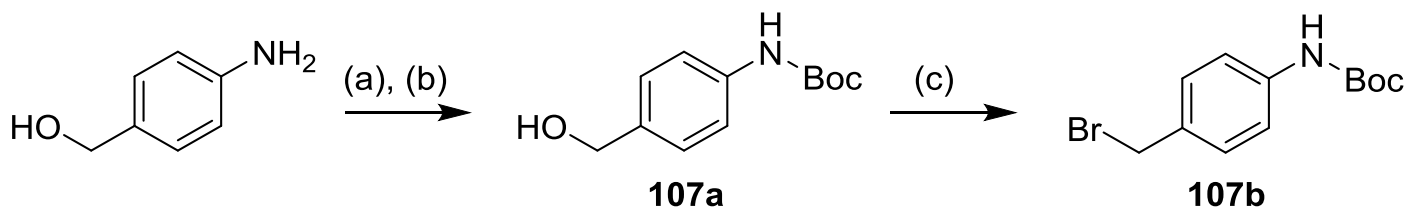

Scheme S1: Two-step synthesis of the benzylating agent 107b. (a) Boc-anhydride, $\mathrm{Na}_{2} \mathrm{CO}_{3}$, $\mathrm{MeOH}, \mathrm{rt}, 1 \mathrm{~h}$; (b) $1 \mathrm{M} \mathrm{HCl}$; (c) $\mathrm{PBr}_{3}$, dietheyl ether, $0{ }^{\circ} \mathrm{C}, 30 \mathrm{~min}$.

\section{$N_{\varepsilon}$-Boc-(4-amino)benzyl alcohol (107a)}

According to the described procedure, ${ }^{1}$ a solution of 4-aminobenzyl alcohol $(1.67 \mathrm{~g}, 13.6$ mmol, 1 equiv.), di-tert-butyl dicarbonate (3.26 g, 14.9 mmol, 1.1 equiv.) and $\mathrm{Na}_{2} \mathrm{CO}_{3}(1.58$ g, 14.9 mmol, 1.1 equiv. $)$ in methanol $(80 \mathrm{~mL})$ was stirred for $1 \mathrm{~h}$ at room temperature. The reaction mixture acidified with $1 \mathrm{M} \mathrm{HCl}$, and extracted with DCM $(3 \times 30 \mathrm{~mL})$. The combined organic phases were dried over sodium sulfate and then concentrated under reduced pressure. The crude 107a obtained as yellow solid (920 mg, 28\% yield) was used as such for next step without further purification. ${ }^{1} \mathrm{H}$ NMR $\left(300 \mathrm{MHz}, \mathrm{CDCl}_{3}\right) \delta 7.35(\mathrm{~d}, J=8.6 \mathrm{~Hz}, 2 \mathrm{H}), 7.29(\mathrm{~d}, J$ $=8.6 \mathrm{~Hz}, 2 \mathrm{H}), 6.47(\mathrm{~s}, 1 \mathrm{H}), 4.63(\mathrm{~s}, 2 \mathrm{H}), 1.52(\mathrm{~s}, 9 \mathrm{H}) ; \mathrm{HRMS}(\mathrm{ESI}): \mathrm{m} / z[\mathrm{M}+\mathrm{Na}]^{+}$calcd for $\mathrm{C}_{12} \mathrm{H}_{17} \mathrm{NO}_{3} \mathrm{Na}: 246.1101$, found: 246.1106.

\section{$N_{\varepsilon}$-Boc-(4-amino)benzyl bromide (107b)}

According to the described procedure, ${ }^{2}$ a cold $\left(0{ }^{\circ} \mathrm{C}\right)$ solution of $\mathbf{1 0 7 a}(815 \mathrm{mg}, 3.65 \mathrm{mmol})$ in diethyl ether $(50 \mathrm{ml})$ was treated with phosphorus tribromide $(0.11 \mathrm{ml}, 1.22 \mathrm{mmol})$ and the reaction mixture was stirred at $0{ }^{\circ} \mathrm{C}$ for $30 \mathrm{~min}$. The reaction mixture was then poured into ice and extracted with ether. The organic layer was dried over sodium sulfate and concentrated. The crude 107b obtained as yellow solid (900 mg, $86 \%$ yield) was taken as such for next step without further purification. ${ }^{1} \mathrm{H}$ NMR $\left(300 \mathrm{MHz} \mathrm{CDCl}_{3}\right) \delta 7.38-7.28(\mathrm{~m}, 4 \mathrm{H}), 6.49(\mathrm{~s}, 1 \mathrm{H})$, $4.48(\mathrm{~s}, 2 \mathrm{H}), 1.52(\mathrm{~s}, 9 \mathrm{H})$; HRMS (ESI): $m / z[\mathrm{M}+\mathrm{Na}]^{+}$calcd for $\mathrm{C}_{12} \mathrm{H}_{16} \mathrm{BrNO}_{2} \mathrm{Na}: 308.0257$, found: 308.0241 . 


\section{Thrombin assay}

The assay was performed as described before. ${ }^{3}$ The continuous fluorimetric assay was done in black 96 well V-bottom plates (Greiner Bio-One, Germnay), on a BMG Labtech Fluostar OPTIMA microtiter fluorescence plate reader using excitation and emission wavelengths of $355 \mathrm{~nm}$ and $460 \mathrm{~nm}$, respectively. The inhibitors (final concentration $25 \mu \mathrm{M}$, from $10 \mathrm{mM}$ stock solutions in DMSO) were preincubated for 15 min with thrombin (10 $\mathrm{nM})$ in the assay buffer (50 mM Tris-HCl pH 7.5, $150 \mathrm{mM} \mathrm{NaCl,} \mathrm{0.05 \%} \mathrm{Tween} \mathrm{20).} \mathrm{Subsequently,} \mathrm{the}$ enzymatic cleavage reaction was initiated by addition of the Boc-Val-Pro-Arg-AMC (Bachem) substrate $(50 \mu \mathrm{M})$. The enzymatic activity was monitored for $10 \mathrm{~min}$ and determined as slope per second (relative fluorescence units per second). Percentage inhibition was calculated relative to a positive control (without the inhibitor). All experiments were performed in triplicate and averaged.

\section{Tryspsin assay}

The inhibition of trypsin was determined as described before. ${ }^{4}$ The continuous fluorimetric assay was carried out in black 96 well V-bottom plates (Greiner Bio-One, Germnay), on a BMG Labtech Fluostar OPTIMA microtiter fluorescence plate reader using excitation and emission wavelengths of $355 \mathrm{~nm}$ and $460 \mathrm{~nm}$, respectively. The inhibitors (final concentration $25 \mu \mathrm{M}$, from $10 \mathrm{mM}$ stock solutions in DMSO) were preincubated for $15 \mathrm{~min}$ with tryspsin (1 $\mathrm{nM})$ in the assay buffer (50 mM Tris- $\mathrm{HCl} \mathrm{pH} 7.5,150 \mathrm{mM} \mathrm{NaCl}, 0.05 \%$ Tween 20). Upon addition of the Boc-Val-Pro-Arg-AMC (Bachem) substrate $(50 \mu \mathrm{M})$, the enzymatic activity was initiated. Percentage inhibition was calculated relative to a positive control (without the inhibitor). All experiments were performed in triplicate and averaged. 


\section{Tryptophan quenching assays}

The tryptophan quenching assays were performed as previously described by Bodenreider et al. $^{5}$ Dengue protease $(0.2 \mu \mathrm{M})$ or WNV protease $(0.5 \mu \mathrm{M})$ was titrated with different concentrations $(0-48 \mu \mathrm{M})$ of compound 104 in the same buffer used for the enzymatic assays, and samples were incubated for $1 \mathrm{~h}$ at room temperature. For the fluorescence displacement experiments, the protease was incubated with the inhibitor $(48 \mu \mathrm{M})$ and aprotinin $(10 \mu \mathrm{M})$ or compound $83(10 \mu \mathrm{M})$ under the same conditions. To account for internal fluorescence or inner filter effects, the autofluorescence of each enzyme in the presence of aprotinin $(10 \mu \mathrm{M})$ or compound $83(10 \mu \mathrm{M})$ was additionally determined, and used for correcting the obtained displacement results. Fluorescence emission at $340 \mathrm{~nm}$ was monitored on a Tecan Safire II instrument (excitation at $280 \mathrm{~nm}$ ). All determinations were performed in duplicate.

\section{Selectivity against thrombin and trypsin}

Table S1: Screening results of peptides from Table 1 against thrombin.

\begin{tabular}{|c|c|}
\hline No. & THR \% ${ }^{a}$ \\
\hline $\mathbf{I}^{6}$ & n.i. \\
\hline 23 & 9.1 \\
\hline 24 & n.i. \\
\hline 25 & 5.0 \\
\hline 26 & 6.2 \\
\hline 27 & n.i. \\
\hline 28 & n.i. \\
\hline 29 & n.i. \\
\hline 30 & 10.0 \\
\hline 31 & n.i. \\
\hline 32 & 8.9 \\
\hline 33 & 8.7 \\
\hline \multicolumn{2}{|c|}{$\begin{array}{l}\text { a Percent inhibition of thrombin (inhibitor } 25 \mu \mathrm{M} \text {, substrate } 50 \mu \mathrm{M} \text { ). n.i. = no } \\
\text { inhibition. All measurements were carried out in triplicate. Standard deviations } \\
\text { were below } 10 \% \text {. }\end{array}$} \\
\hline
\end{tabular}


Table S2: Screening results of peptides from Table 2 against thrombin.

\begin{tabular}{|c|c|c|c|}
\hline No. & THR \% ${ }^{a}$ & No. & THR \% ${ }^{a}$ \\
\hline 27 & n.i. & 42 & 9.7 \\
\hline 34 & 10.7 & 43 & 7.7 \\
\hline 35 & 11.3 & 44 & 11.7 \\
\hline 36 & 5.7 & 45 & 6.2 \\
\hline 37 & 19.8 & 46 & 6.4 \\
\hline 38 & 12.5 & 47 & 7.7 \\
\hline 39 & 11.9 & 48 & 10.7 \\
\hline 40 & 16.8 & 49 & 8.3 \\
\hline 41 & 14.3 & 50 & 4.9 \\
\hline 109 & 7.2 & & \\
\hline
\end{tabular}

Table S3: Screening results of peptides from Table 3 against thrombin.

\begin{tabular}{|c|c|c|c|}
\hline No. & THR \% ${ }^{a}$ & No. & THR $\%^{a}$ \\
\hline 27 & n.i. & 67 & 7.5 \\
\hline 51 & n.i. & 68 & n.i. \\
\hline 52 & n.i. & 69 & 17.2 \\
\hline 53 & 5.1 & 70 & 4.3 \\
\hline 54 & 8.9 & 71 & n.i. \\
\hline 55 & n.i. & 72 & 10.2 \\
\hline 56 & 13.5 & 73 & 10.5 \\
\hline 57 & 16.1 & 74 & 13.5 \\
\hline 58 & n.i. & 75 & 18.8 \\
\hline 59 & 6.4 & 76 & n.i. \\
\hline 60 & n.i. & 77 & 7.8 \\
\hline 61 & n.i. & 78 & n.i. \\
\hline 62 & 24.1 & 79 & 18.7 \\
\hline 63 & 35.3 & 80 & 13.0 \\
\hline 64 & 9.0 & 81 & n.i. \\
\hline 65 & 7.8 & 82 & 10.8 \\
\hline 66 & 6.6 & & \\
\hline
\end{tabular}


Table S4: Screening results of peptides from Table 4 against thrombin and trypsin.

\begin{tabular}{|c|c|c|}
\hline No. & THR $\%^{a}$ & Trypsin \% \\
\hline 27 & n.i. & 18.9 \\
\hline 83 & 8.9 & 14.4 \\
\hline 84 & 7.8 & 6.5 \\
\hline 85 & n.i. & 8.0 \\
\hline 86 & 11.1 & n.i. \\
\hline 87 & 7.8 & n.i. \\
\hline 88 & 14.2 & 8.9 \\
\hline 89 & 22.4 & 37.7 \\
\hline 90 & 10.7 & n.i. \\
\hline 91 & 21.9 & 59.1 \\
\hline 92 & 17.3 & 12.5 \\
\hline 93 & 14.4 & 29.0 \\
\hline 94 & 9.1 & 19.7 \\
\hline 95 & 16.6 & n.i. \\
\hline 96 & 20.1 & n.i. \\
\hline 97 & 25.9 & 5.7 \\
\hline 98 & 11.2 & n.i. \\
\hline 99 & 11.7 & 14.0 \\
\hline 100 & 11.9 & 14.6 \\
\hline 101 & n.i. & 10.6 \\
\hline 102 & 19.7 & 11.7 \\
\hline 103 & 24.7 & n.i. \\
\hline 104 & 25.6 & 23.6 \\
\hline 105 & 8.3 & n.i. \\
\hline 106 & 9.5 & 10.6 \\
\hline \multicolumn{3}{|c|}{$\begin{array}{l}{ }^{\mathrm{a}} \text { Percent inhibition of thrombin (inhibitor } 25 \mu \mathrm{M} \text {, substrate } 50 \mu \mathrm{M} \text { ). }{ }^{\mathrm{b}} \text { Percer } \\
\text { inhibition of trypsin (inhibitor } 25 \mu \mathrm{M} \text {, substrate } 50 \mu \mathrm{M} \text { ). n.i. = no inhibition. A } \\
\text { measurements were carried out in triplicate. Standard deviations were below } 10 \%\end{array}$} \\
\hline
\end{tabular}




\section{Binding mode analysis by tryptophan quenching assays}
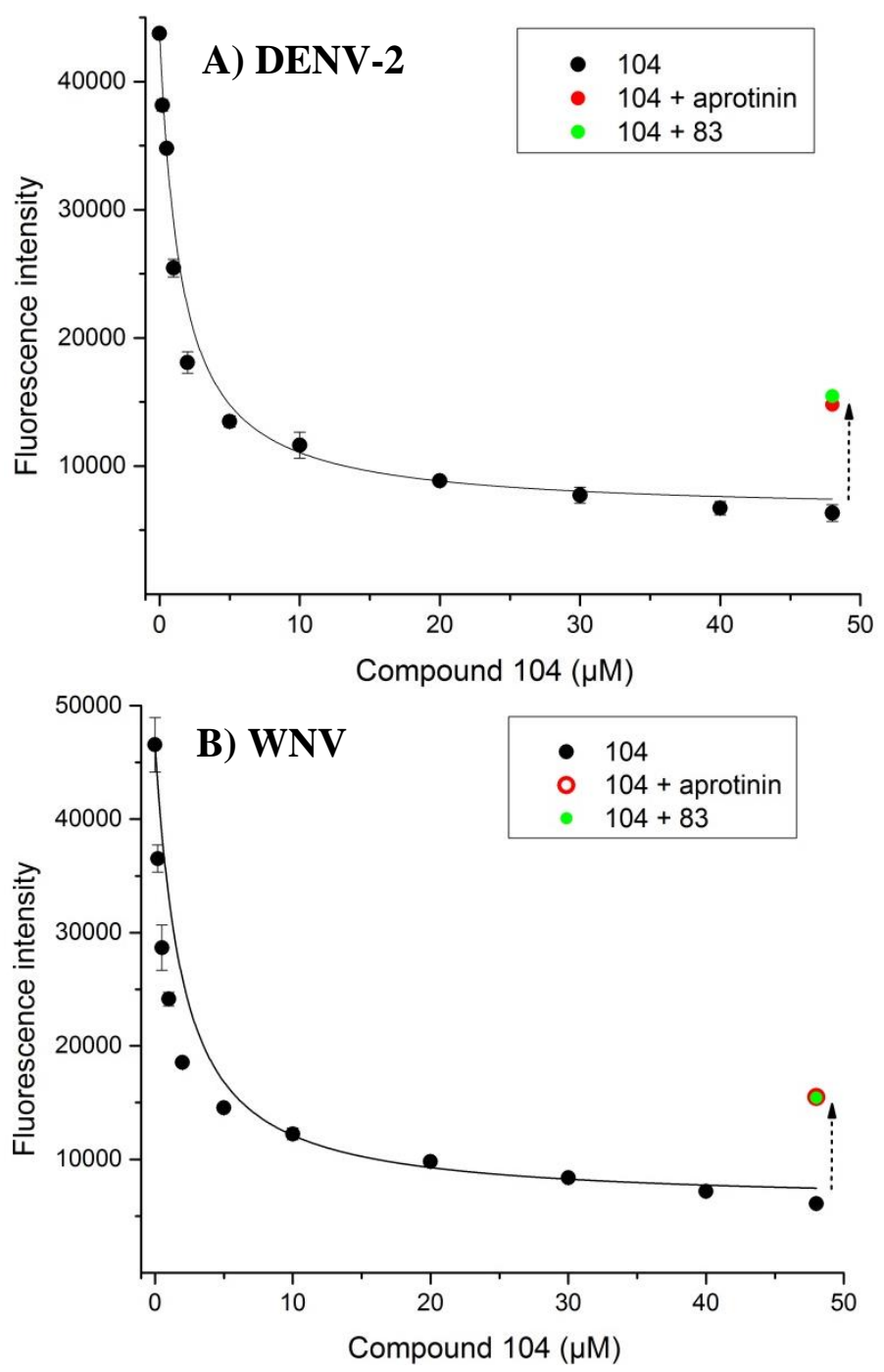

Figure S1: The addition of $\mathbf{1 0 4}$ to DENV-2 protease (A) or WNV protease (B) led to a concentration-dependent quenching of the fluorescence of the tryptophan residues in the protease. Plotting the fluorescence intensity versus inhibitor concentration shows a classical binding isotherm. Further evidence for binding of $\mathbf{1 0 4}$ to dengue or WNV NS2B-NS3 active site was provided by using aprotinin, a known competitive ligand for both proteases. When aprotinin $(10 \mu \mathrm{M})$ was added to wells containing the protease and compound 104, a partial restoration of fluorescence was observed. This indicates that aprotinin can displace the binding of $\mathbf{1 0 4}$ and thus confirms that the latter binds in the same pocket as aprotinin. A 
similar restoration of fluorescence by displacement of $\mathbf{1 0 4}$ from the protease active site could be also observed by competitive binding of the more affine inhibitor $83(10 \mu \mathrm{M})$.

\section{Kinetics studies for compound 83}

Plotting the obtained $\mathrm{IC}_{50}$-values for compound $\mathbf{8 3}$ at DENV-2 or WNV proteases against the substrate concentration in Cheng-Prussof plot reveals a competitive inhibition mechanism.
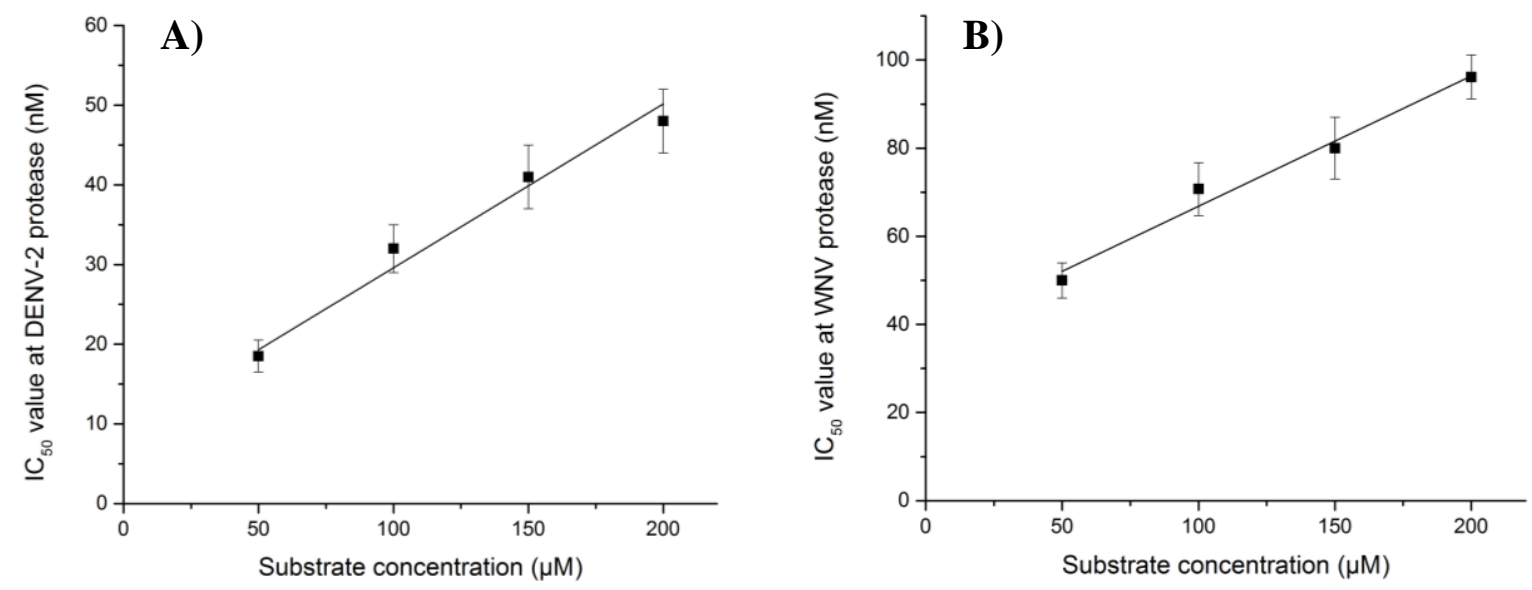

Figure S2: Kinetic studies for compound $\mathbf{8 3}$ at DENV-2 and WNV proteases. A) ChengPrusoff plot of compound 83 at DENV-2 protease. B) Cheng-Prusoff plot of compound $\mathbf{8 3}$ at WNV protease. Both plots indicate a competitive inhibition mechanism.

\section{Peptides HRMS and HPLC Data}

The peptides were obtained as solid white powders after lyophilization and characterized by HR-ESI mass spectrometry. Purity was determined by HPLC using method A. All evaluated compounds were obtained with a purity of at least $95 \%$, unless otherwise indicated.

\begin{tabular}{|c|c|c|c|c|c|}
\hline \multirow{2}{*}{ No. } & \multicolumn{3}{|c|}{ HRMS (ESI) for $[\mathrm{M}+\mathrm{H}]^{+}$} & \multirow{2}{*}{$\begin{array}{c}\mathrm{HPLC} \boldsymbol{t}_{\mathrm{R}} \\
\quad(\mathrm{min})\end{array}$} & \multirow{2}{*}{$\begin{array}{c}\text { HPLC } \\
\text { purity } \\
(254 \mathrm{~nm})\end{array}$} \\
\hline & Molecular Formula & Calculated & Found & & \\
\hline 23 & $\mathrm{C}_{27} \mathrm{H}_{39} \mathrm{~N}_{8} \mathrm{O}_{4}$ & 539.3089 & 539.3090 & 1.95 & $>95 \%$ \\
\hline 24 & $\mathrm{C}_{27} \mathrm{H}_{39} \mathrm{~N}_{8} \mathrm{O}_{5}$ & 555.3038 & 555.3041 & 1.71 & $>95 \%$ \\
\hline 25 & $\mathrm{C}_{27} \mathrm{H}_{39} \mathrm{~N}_{8} \mathrm{O}_{5}$ & 555.3038 & 555.3029 & 1.68 & $>95 \%$ \\
\hline 26 & $\mathrm{C}_{34} \mathrm{H}_{45} \mathrm{~N}_{8} \mathrm{O}_{5}$ & 645.3507 & 645.3481 & 2.84 & $>95 \%$ \\
\hline 27 & $\mathrm{C}_{34} \mathrm{H}_{45} \mathrm{~N}_{8} \mathrm{O}_{5}$ & 645.3507 & 645.3493 & 2.83 & $>95 \%$ \\
\hline
\end{tabular}




\begin{tabular}{|c|c|c|c|c|c|}
\hline \multirow{2}{*}{ No. } & \multicolumn{3}{|c|}{ HRMS (ESI) for $[\mathrm{M}+\mathrm{H}]^{+}$} & \multirow{2}{*}{$\begin{array}{c}\mathrm{HPLC} \boldsymbol{t}_{\mathrm{R}} \\
\quad(\mathrm{min})\end{array}$} & \multirow{2}{*}{$\begin{array}{c}\text { HPLC } \\
\text { purity } \\
(254 \text { nm) }\end{array}$} \\
\hline & Molecular Formula & Calculated & Found & & \\
\hline 28 & $\mathrm{C}_{28} \mathrm{H}_{33} \mathrm{~N}_{4} \mathrm{O}_{4}$ & 489.2498 & 489.2484 & 3.01 & $>95 \%$ \\
\hline 29 & $\mathrm{C}_{28} \mathrm{H}_{33} \mathrm{~N}_{6} \mathrm{O}_{4}$ & 517.2558 & 517.2538 & 3.07 & $>95 \%$ \\
\hline 30 & $\mathrm{C}_{34} \mathrm{H}_{45} \mathrm{~N}_{8} \mathrm{O}_{5}$ & 645.3507 & 645.3507 & 2.77 & $>95 \%$ \\
\hline 31 & $\mathrm{C}_{34} \mathrm{H}_{45} \mathrm{~N}_{8} \mathrm{O}_{5}$ & 645.3507 & 645.3486 & 2.86 & $>95 \%$ \\
\hline 32 & $\mathrm{C}_{34} \mathrm{H}_{45} \mathrm{~N}_{8} \mathrm{O}_{5}$ & 645.3507 & 645.3507 & 2.77 & $>95 \%$ \\
\hline 33 & $\mathrm{C}_{34} \mathrm{H}_{45} \mathrm{~N}_{8} \mathrm{O}_{5}$ & 645.3507 & 645.3503 & 2.77 & $>95 \%$ \\
\hline 34 & $\mathrm{C}_{35} \mathrm{H}_{44} \mathrm{~N}_{9} \mathrm{O}_{5}$ & 670.3460 & 670.3445 & 2.69 & $>95 \%$ \\
\hline 35 & $\mathrm{C}_{34} \mathrm{H}_{44} \mathrm{BrN}_{8} \mathrm{O}_{5}$ & 723.2613 & 723.2597 & 3.12 & $>95 \%$ \\
\hline 36 & $\mathrm{C}_{34} \mathrm{H}_{44} \mathrm{FN}_{8} \mathrm{O}_{5}$ & 663.3413 & 663.3409 & 2.84 & $>95 \%$ \\
\hline 37 & $\mathrm{C}_{34} \mathrm{H}_{44} \mathrm{ClN}_{8} \mathrm{O}_{5}$ & 679.3118 & 679.3118 & 3.05 & $>95 \%$ \\
\hline 38 & $\mathrm{C}_{35} \mathrm{H}_{44} \mathrm{~F}_{3} \mathrm{~N}_{8} \mathrm{O}_{5}$ & 713.3381 & 713.3376 & 3.20 & $>95 \%$ \\
\hline 39 & $\mathrm{C}_{35} \mathrm{H}_{44} \mathrm{~F}_{3} \mathrm{~N}_{8} \mathrm{O}_{6}$ & 729.3330 & 729.3331 & 3.26 & $>95 \%$ \\
\hline 40 & $\mathrm{C}_{34} \mathrm{H}_{44} \mathrm{BrN}_{8} \mathrm{O}_{5}$ & 723.2613 & 723.2593 & 3.05 & $>95 \%$ \\
\hline 41 & $\mathrm{C}_{35} \mathrm{H}_{44} \mathrm{~F}_{3} \mathrm{~N}_{8} \mathrm{O}_{5}$ & 713.3381 & 713.3376 & 3.14 & $>95 \%$ \\
\hline 42 & $\mathrm{C}_{34} \mathrm{H}_{44} \mathrm{ClN}_{8} \mathrm{O}_{5}$ & 679.3118 & 679.3110 & 3.03 & $>95 \%$ \\
\hline 43 & $\mathrm{C}_{34} \mathrm{H}_{44} \mathrm{ClN}_{8} \mathrm{O}_{5}$ & 679.3118 & 679.3115 & 3.05 & $>95 \%$ \\
\hline 44 & $\mathrm{C}_{34} \mathrm{H}_{43} \mathrm{Cl}_{2} \mathrm{~N}_{8} \mathrm{O}_{5}$ & 713.2728 & 713.2714 & 3.10 & $95 \%$ \\
\hline 45 & $\mathrm{C}_{34} \mathrm{H}_{43} \mathrm{Cl}_{2} \mathrm{~N}_{8} \mathrm{O}_{5}$ & 713.2728 & 713.2720 & 3.29 & $>95 \%$ \\
\hline 46 & $\mathrm{C}_{35} \mathrm{H}_{47} \mathrm{~N}_{8} \mathrm{O}_{6}$ & 675.3613 & 675.3611 & 2.77 & $>95 \%$ \\
\hline 47 & $\mathrm{C}_{35} \mathrm{H}_{47} \mathrm{~N}_{8} \mathrm{O}_{5}$ & 659.3664 & 659.3653 & 2.93 & $>95 \%$ \\
\hline 48 & $\mathrm{C}_{38} \mathrm{H}_{53} \mathrm{~N}_{8} \mathrm{O}_{5}$ & 701.4133 & 701.4105 & 3.18 & $>95 \%$ \\
\hline 49 & $\mathrm{C}_{38} \mathrm{H}_{47} \mathrm{~N}_{8} \mathrm{O}_{5}$ & 695.3664 & 695.3651 & 2.94 & $>95 \%$ \\
\hline 50 & $\mathrm{C}_{35} \mathrm{H}_{45} \mathrm{~N}_{8} \mathrm{O}_{6}$ & 673.3457 & 673.3431 & 2.54 & $>95 \%$ \\
\hline 51 & $\mathrm{C}_{33} \mathrm{H}_{44} \mathrm{~N}_{9} \mathrm{O}_{5}$ & 646.3460 & 646.3444 & 2.38 & $>95 \%$ \\
\hline 52 & $\mathrm{C}_{32} \mathrm{H}_{43} \mathrm{~N}_{8} \mathrm{O}_{6}$ & 635.3300 & 635.3279 & 2.60 & $>95 \%$ \\
\hline 53 & $\mathrm{C}_{32} \mathrm{H}_{43} \mathrm{~N}_{8} \mathrm{O}_{5} \mathrm{~S}$ & 651.3072 & 651.3053 & 2.77 & $>95 \%$ \\
\hline 54 & $\mathrm{C}_{32} \mathrm{H}_{43} \mathrm{~N}_{8} \mathrm{O}_{5} \mathrm{~S}$ & 651.3072 & 651.3063 & 2.69 & $>95 \%$ \\
\hline 55 & $\mathrm{C}_{31} \mathrm{H}_{42} \mathrm{~N}_{9} \mathrm{O}_{5} \mathrm{~S}$ & 652.3024 & 652.3024 & 2.62 & $95 \%$ \\
\hline 56 & $\mathrm{C}_{31} \mathrm{H}_{42} \mathrm{~N}_{9} \mathrm{O}_{5} \mathrm{~S}$ & 652.3024 & 652.3016 & 2.66 & $>95 \%$ \\
\hline 57 & $\mathrm{C}_{31} \mathrm{H}_{42} \mathrm{~N}_{9} \mathrm{O}_{5} \mathrm{~S}$ & 652.3024 & 652.3022 & 2.54 & $>95 \%$ \\
\hline 58 & $\mathrm{C}_{34} \mathrm{H}_{51} \mathrm{~N}_{8} \mathrm{O}_{5}$ & 651.3977 & 651.3973 & 2.88 & $>95 \%$ \\
\hline 59 & $\mathrm{C}_{33} \mathrm{H}_{49} \mathrm{~N}_{8} \mathrm{O}_{5}$ & 637.3820 & 637.3824 & 2.72 & $92 \%$ \\
\hline 60 & $\mathrm{C}_{32} \mathrm{H}_{47} \mathrm{~N}_{8} \mathrm{O}_{5}$ & 623.3664 & 623.3652 & 2.60 & $>95 \%$ \\
\hline 61 & $\mathrm{C}_{31} \mathrm{H}_{45} \mathrm{~N}_{8} \mathrm{O}_{5}$ & 609.3507 & 609.3507 & 2.53 & $>95 \%$ \\
\hline 62 & $\mathrm{C}_{32} \mathrm{H}_{42} \mathrm{ClN}_{8} \mathrm{O}_{5} \mathrm{~S}$ & 685.2682 & 685.2681 & 2.89 & $95 \%$ \\
\hline 63 & $\mathrm{C}_{32} \mathrm{H}_{42} \mathrm{ClN}_{8} \mathrm{O}_{5} \mathrm{~S}$ & 685.2682 & 685.2669 & 3.00 & $>95 \%$ \\
\hline 64 & $\mathrm{C}_{33} \mathrm{H}_{45} \mathrm{~N}_{8} \mathrm{O}_{5} \mathrm{~S}$ & 665.3228 & 665.3230 & 2.88 & $>95 \%$ \\
\hline 65 & $\mathrm{C}_{34} \mathrm{H}_{44} \mathrm{FN}_{8} \mathrm{O}_{5}$ & 663.3413 & 663.3405 & 2.84 & $>95 \%$ \\
\hline 66 & $\mathrm{C}_{34} \mathrm{H}_{44} \mathrm{FN}_{8} \mathrm{O}_{5}$ & 663.3413 & 663.3408 & 2.81 & $>95 \%$ \\
\hline 67 & $\mathrm{C}_{34} \mathrm{H}_{44} \mathrm{FN}_{8} \mathrm{O}_{5}$ & 663.3413 & 663.3396 & 2.79 & $95 \%$ \\
\hline 68 & $\mathrm{C}_{35} \mathrm{H}_{44} \mathrm{~F}_{3} \mathrm{~N}_{8} \mathrm{O}_{5}$ & 713.3381 & 713.3378 & 2.86 & $>95 \%$ \\
\hline 69 & $\mathrm{C}_{35} \mathrm{H}_{45} \mathrm{~N}_{8} \mathrm{O}_{6}$ & 673.3457 & 673.3442 & 2.71 & $90 \%$ \\
\hline 70 & $\mathrm{C}_{35} \mathrm{H}_{45} \mathrm{~N}_{8} \mathrm{O}_{6}$ & 673.3457 & 673.3431 & 2.77 & $>95 \%$ \\
\hline 71 & $\mathrm{C}_{36} \mathrm{H}_{47} \mathrm{~N}_{8} \mathrm{O}_{6}$ & 687.3613 & 687.3588 & 2.64 & $94 \%$ \\
\hline 72 & $\mathrm{C}_{36} \mathrm{H}_{47} \mathrm{~N}_{8} \mathrm{O}_{5}$ & 671.3664 & 671.3668 & 3.03 & $>95 \%$ \\
\hline
\end{tabular}




\begin{tabular}{|c|c|c|c|c|c|}
\hline \multirow{2}{*}{ No. } & \multicolumn{3}{|c|}{ 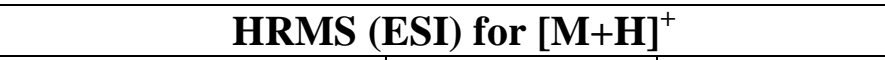 } & \multirow{2}{*}{$\begin{array}{c}\mathrm{HPLC} \boldsymbol{t}_{\mathrm{R}} \\
\quad(\mathrm{min})\end{array}$} & \multirow{2}{*}{$\begin{array}{c}\text { HPLC } \\
\text { purity } \\
(254 \mathrm{~nm})\end{array}$} \\
\hline & Molecular Formula & Calculated & Found & & \\
\hline 73 & $\mathrm{C}_{36} \mathrm{H}_{46} \mathrm{ClN}_{8} \mathrm{O}_{5}$ & 705.3274 & 705.3254 & 3.26 & $>95 \%$ \\
\hline 74 & $\mathrm{C}_{36} \mathrm{H}_{49} \mathrm{~N}_{8} \mathrm{O}_{5}$ & 673.3820 & 673.3807 & 2.90 & $>95 \%$ \\
\hline 75 & $\mathrm{C}_{34} \mathrm{H}_{43} \mathrm{~N}_{8} \mathrm{O}_{5} \mathrm{~S}_{2}$ & 707.2792 & 707.2791 & 3.05 & $95 \%$ \\
\hline 76 & $\mathrm{C}_{34} \mathrm{H}_{43} \mathrm{~N}_{8} \mathrm{O}_{5} \mathrm{~S}_{2}$ & 707.2792 & 707.2788 & 3.04 & $94 \%$ \\
\hline 77 & $\mathrm{C}_{36} \mathrm{H}_{45} \mathrm{~N}_{8} \mathrm{O}_{5} \mathrm{~S}$ & 701.3228 & 701.3220 & 3.13 & $>95 \%$ \\
\hline 78 & $\mathrm{C}_{34} \mathrm{H}_{45} \mathrm{~N}_{8} \mathrm{O}_{7} \mathrm{~S}$ & 709.3126 & 709.3120 & 2.83 & $90 \%$ \\
\hline 79 & $\mathrm{C}_{36} \mathrm{H}_{45} \mathrm{~N}_{8} \mathrm{O}_{5} \mathrm{~S}_{2}$ & 733.2949 & 733.2940 & 3.27 & $94 \%$ \\
\hline 80 & $\mathrm{C}_{36} \mathrm{H}_{46} \mathrm{~N}_{9} \mathrm{O}_{5} \mathrm{~S}$ & 716.3337 & 716.3325 & 3.02 & $94 \%$ \\
\hline 81 & $\mathrm{C}_{38} \mathrm{H}_{47} \mathrm{~N}_{8} \mathrm{O}_{5} \mathrm{~S}$ & 727.3385 & 727.3367 & 3.32 & $94 \%$ \\
\hline 82 & $\mathrm{C}_{38} \mathrm{H}_{47} \mathrm{~N}_{8} \mathrm{O}_{5} \mathrm{~S}$ & 727.3385 & 727.3379 & 3.33 & $>95 \%$ \\
\hline 83 & $\mathrm{C}_{32} \mathrm{H}_{41} \mathrm{~F}_{3} \mathrm{~N}_{9} \mathrm{O}_{5} \mathrm{~S}$ & 720.2898 & 720.2896 & 3.11 & $>95 \%$ \\
\hline 84 & $\mathrm{C}_{32} \mathrm{H}_{44} \mathrm{~N}_{9} \mathrm{O}_{6} \mathrm{~S}$ & 682.3130 & 682.3123 & 2.69 & $>95 \%$ \\
\hline 85 & $\mathrm{C}_{31} \mathrm{H}_{40} \mathrm{Cl}_{2} \mathrm{~N}_{9} \mathrm{O}_{5} \mathrm{~S}$ & 720.2245 & 720.2234 & 2.96 & $>95 \%$ \\
\hline 86 & $\mathrm{C}_{33} \mathrm{H}_{42} \mathrm{~F}_{3} \mathrm{~N}_{8} \mathrm{O}_{5} \mathrm{~S}$ & 719.2945 & 719.2945 & 3.15 & $>95 \%$ \\
\hline 87 & $\mathrm{C}_{32} \mathrm{H}_{42} \mathrm{FN}_{8} \mathrm{O}_{5} \mathrm{~S}$ & 669.2977 & 669.2961 & 2.79 & $>95 \%$ \\
\hline 88 & $\mathrm{C}_{33} \mathrm{H}_{45} \mathrm{~N}_{8} \mathrm{O}_{6} \mathrm{~S}$ & 681.3177 & 681.3179 & 2.71 & $>95 \%$ \\
\hline 89 & $\mathrm{C}_{32} \mathrm{H}_{42} \mathrm{BrN}_{8} \mathrm{O}_{5} \mathrm{~S}$ & 729.2177 & 729.2168 & 3.07 & $>95 \%$ \\
\hline 90 & $\mathrm{C}_{32} \mathrm{H}_{41} \mathrm{Cl}_{2} \mathrm{~N}_{8} \mathrm{O}_{5} \mathrm{~S}$ & 719.2292 & 719.2281 & 3.22 & $>95 \%$ \\
\hline 91 & $\mathrm{C}_{33} \mathrm{H}_{42} \mathrm{BrN}_{8} \mathrm{O}_{6} \mathrm{~S}$ & 757.2126 & 757.2126 & 2.87 & $>95 \%$ \\
\hline 92 & $\mathrm{C}_{32} \mathrm{H}_{41} \mathrm{Cl}_{2} \mathrm{~N}_{8} \mathrm{O}_{5} \mathrm{~S}$ & 719.2292 & 719.2284 & 3.22 & $>95 \%$ \\
\hline 93 & $\mathrm{C}_{36} \mathrm{H}_{50} \mathrm{ClN}_{8} \mathrm{O}_{5} \mathrm{~S}$ & 741.3308 & 741.3294 & 3.34 & $>95 \%$ \\
\hline 94 & $\mathrm{C}_{32} \mathrm{H}_{41} \mathrm{Cl}_{2} \mathrm{~N}_{8} \mathrm{O}_{5} \mathrm{~S}$ & 719.2292 & 719.2289 & 3.12 & $>95 \%$ \\
\hline 95 & $\mathrm{C}_{36} \mathrm{H}_{50} \mathrm{ClN}_{8} \mathrm{O}_{5} \mathrm{~S}$ & 741.3308 & 741.3307 & 3.24 & $>95 \%$ \\
\hline 96 & $\mathrm{C}_{38} \mathrm{H}_{51} \mathrm{~N}_{8} \mathrm{O}_{5} \mathrm{~S}_{2}$ & 763.3418 & 763.3403 & 3.37 & $>95 \%$ \\
\hline 97 & $\mathrm{C}_{34} \mathrm{H}_{41} \mathrm{Cl}_{2} \mathrm{~N}_{8} \mathrm{O}_{5} \mathrm{~S}_{2}$ & 775.2013 & 775.1988 & 3.28 & $>95 \%$ \\
\hline 98 & $\mathrm{C}_{34} \mathrm{H}_{42} \mathrm{ClN}_{8} \mathrm{O}_{5} \mathrm{~S}_{2}$ & 741.2403 & 741.2389 & 3.26 & $>95 \%$ \\
\hline 99 & $\mathrm{C}_{35} \mathrm{H}_{42} \mathrm{~F}_{3} \mathrm{~N}_{8} \mathrm{O}_{5} \mathrm{~S}_{2}$ & 775.2666 & 775.2656 & 3.32 & $>95 \%$ \\
\hline 100 & $\mathrm{C}_{35} \mathrm{H}_{42} \mathrm{~F}_{3} \mathrm{~N}_{8} \mathrm{O}_{5} \mathrm{~S}_{2}$ & 775.2666 & 775.2666 & 3.39 & $>95 \%$ \\
\hline 101 & $\mathrm{C}_{37} \mathrm{H}_{44} \mathrm{~F}_{3} \mathrm{~N}_{8} \mathrm{O}_{5} \mathrm{~S}$ & 769.3102 & 769.3085 & 3.47 & $>95 \%$ \\
\hline 102 & $\mathrm{C}_{37} \mathrm{H}_{44} \mathrm{~F}_{3} \mathrm{~N}_{8} \mathrm{O}_{5} \mathrm{~S}$ & 729.3102 & 769.3103 & 3.35 & $>95 \%$ \\
\hline 103 & $\mathrm{C}_{36} \mathrm{H}_{43} \mathrm{Cl}_{2} \mathrm{~N}_{8} \mathrm{O}_{5} \mathrm{~S}$ & 769.2449 & 769.2455 & 3.33 & $>95 \%$ \\
\hline 104 & $\mathrm{C}_{37} \mathrm{H}_{47} \mathrm{~N}_{8} \mathrm{O}_{6} \mathrm{~S}_{2}$ & 763.3054 & 763.3043 & 3.28 & $>95 \%$ \\
\hline 105 & $\mathrm{C}_{36} \mathrm{H}_{43} \mathrm{Cl}_{2} \mathrm{~N}_{8} \mathrm{O}_{5} \mathrm{~S}_{2}$ & 801.2169 & 801.2148 & 3.60 & $>95 \%$ \\
\hline 106 & $\mathrm{C}_{38} \mathrm{H}_{45} \mathrm{Cl}_{2} \mathrm{~N}_{8} \mathrm{O}_{5} \mathrm{~S}$ & 795.2605 & 795.2604 & 3.48 & $>95 \%$ \\
\hline 109 & $\mathrm{C}_{34} \mathrm{H}_{46} \mathrm{~N}_{9} \mathrm{O}_{5}$ & 660.3616 & 660.3628 & 1.88 & $>95 \%$ \\
\hline
\end{tabular}

\section{Characterization of fluorescent peptides}

The following peptides were found to exhibit fluorescence: 79, 104, 105, 82 and 96 . For the bithiophene-capped peptides, 79, 104, 105, excitation and emission wavelengths were $340 \mathrm{~nm}$ and $425 \mathrm{~nm}$, respectively. For 82, excitation wavelength was $313 \mathrm{~nm}$ and emission 
wavelengths was $390 \mathrm{~nm}$. For 96, excitation wavelength was $300 \mathrm{~nm}$ and emission wavelengths was $380 \mathrm{~nm}$.

\section{NMR data for selected peptide inhibitors}

24: ${ }^{1} \mathrm{H}$ NMR $\left(500 \mathrm{MHz}, \mathrm{D}_{2} \mathrm{O}\right) \delta 7.74(\mathrm{dd}, J=8.4,1.1 \mathrm{~Hz}, 2 \mathrm{H}), 7.68-7.63(\mathrm{~m}, 1 \mathrm{H}), 7.54(\mathrm{t}, J$ $=7.7 \mathrm{~Hz}, 2 \mathrm{H}), 7.32(\mathrm{~d}, J=8.7 \mathrm{~Hz}, 2 \mathrm{H}), 6.92(\mathrm{~d}, J=8.7 \mathrm{~Hz}, 2 \mathrm{H}), 5.36(\mathrm{~s}, 1 \mathrm{H}), 4.48-4.43(\mathrm{~m}$, $2 \mathrm{H}), 4.18-4.12(\mathrm{~m}, 1 \mathrm{H}), 3.25-3.18(\mathrm{~m}, 1 \mathrm{H}), 3.17-3.12(\mathrm{~m}, 2 \mathrm{H}), 2.99(\mathrm{t}, J=7.5 \mathrm{~Hz}, 2 \mathrm{H})$, $2.09(\mathrm{~s}, 1 \mathrm{H}), 1.95-1.77(\mathrm{~m}, 5 \mathrm{H}), 1.75-1.62(\mathrm{~m}, 4 \mathrm{H}), 1.61-1.43(\mathrm{~m}, 4 \mathrm{H}), 1.31-1.24(\mathrm{~m}$, $1 \mathrm{H})$.

27: ${ }^{1} \mathrm{H}$ NMR (500 MHz, $\left.\mathrm{CD}_{3} \mathrm{OD}\right) \delta 7.87(\mathrm{dd}, J=8.4,1.3 \mathrm{~Hz}, 2 \mathrm{H}), 7.61-7.57(\mathrm{~m}, 1 \mathrm{H}), 7.50$ $(\mathrm{t}, J=7.6 \mathrm{~Hz}, 2 \mathrm{H}), 7.44(\mathrm{~d}, J=7.5 \mathrm{~Hz}, 2 \mathrm{H}), 7.40-7.30(\mathrm{~m}, 4 \mathrm{H}), 7.03-6.99(\mathrm{~m}, 2 \mathrm{H}), 5.33(\mathrm{~s}$, 1H), $5.11(\mathrm{~s}, 2 \mathrm{H}), 4.56(\mathrm{dd}, J=7.8,6.5 \mathrm{~Hz}, 1 \mathrm{H}), 4.47(\mathrm{dd}, J=9.4,5.1 \mathrm{~Hz}, 1 \mathrm{H}), 3.27(\mathrm{t}, J=$ $7.1 \mathrm{~Hz}, 2 \mathrm{H}), 2.90(\mathrm{t}, J=7.5 \mathrm{~Hz}, 2 \mathrm{H}), 2.08-1.98(\mathrm{~m}, 2 \mathrm{H}), 1.97-1.83(\mathrm{~m}, 3 \mathrm{H}), 1.83-1.58$ $(\mathrm{m}, 6 \mathrm{H}), 1.57-1.39(\mathrm{~m}, 3 \mathrm{H}), 1.31(\mathrm{~s}, 1 \mathrm{H}) .{ }^{13} \mathrm{C} \mathrm{NMR}\left(\mathrm{APT}, 126 \mathrm{MHz}, \mathrm{CD}_{3} \mathrm{OD}\right) \delta$ 175.03, $174.48,173.29,170.53,160.29,138.52,135.05,133.07,130.95,129.94,129.64,129.53$, $128.94,128.51,116.23,71.01,58.04,55.09,54.19,49.00,42.12,40.51,32.07,30.03,27.92$, $26.45,23.65$

83: ${ }^{1} \mathrm{H}$ NMR $\left(500 \mathrm{MHz}, \mathrm{D}_{2} \mathrm{O}\right) \delta 8.02(\mathrm{~d}, J=3.1 \mathrm{~Hz}, 1 \mathrm{H}), 7.92(\mathrm{~d}, J=3.1 \mathrm{~Hz}, 1 \mathrm{H}), 7.76(\mathrm{~d}, J$ $=8.4 \mathrm{~Hz}, 2 \mathrm{H}), 7.66(\mathrm{~d}, J=8.3 \mathrm{~Hz}, 2 \mathrm{H}), 7.37(\mathrm{~d}, J=8.9 \mathrm{~Hz}, 2 \mathrm{H}), 7.11(\mathrm{~d}, J=8.9 \mathrm{~Hz}, 2 \mathrm{H})$, $5.39(\mathrm{~d}, J=4.5 \mathrm{~Hz}, 1 \mathrm{H}), 5.29(\mathrm{~d}, J=6.7 \mathrm{~Hz}, 2 \mathrm{H}), 4.51(\mathrm{dd}, J=7.8,6.5 \mathrm{~Hz}, 1 \mathrm{H}), 4.49-4.43$ (m, 1H), $4.38(\mathrm{dd}, J=8.8,6.2 \mathrm{~Hz}, 1 \mathrm{H}), 3.18(\mathrm{t}, J=6.9 \mathrm{~Hz}, 2 \mathrm{H}), 3.10-3.03(\mathrm{~m}, 1 \mathrm{H}), 3.02-$ $2.99(\mathrm{~m}, 1 \mathrm{H}), 2.94(\mathrm{t}, J=7.7 \mathrm{~Hz}, 2 \mathrm{H}), 2.01-1.75(\mathrm{~m}, 6 \mathrm{H}), 1.75-1.59(\mathrm{~m}, 5 \mathrm{H}), 1.60-1.27$ $(\mathrm{m}, 6 \mathrm{H}), 1.25-1.14(\mathrm{~m}, 1 \mathrm{H})$.

86: ${ }^{1} \mathrm{H}$ NMR $\left(500 \mathrm{MHz}, \mathrm{D}_{2} \mathrm{O}\right) \delta 7.77(\mathrm{dd}, J=3.9,1.1 \mathrm{~Hz}, 2 \mathrm{H}), 7.76-7.74(\mathrm{~m}, 2 \mathrm{H}), 7.66(\mathrm{~d}, J$ $=7.9 \mathrm{~Hz}, 2 \mathrm{H}), 7.39-7.35(\mathrm{~m}, 2 \mathrm{H}), 7.21(\mathrm{dd}, J=5.0,3.8 \mathrm{~Hz}, 1 \mathrm{H}), 7.11(\mathrm{~d}, J=8.5 \mathrm{~Hz}, 2 \mathrm{H})$, 
$5.38(\mathrm{~s}, 1 \mathrm{H}), 5.29(\mathrm{~s}, 2 \mathrm{H}), 4.46(\mathrm{t}, J=6.9 \mathrm{~Hz}, 1 \mathrm{H}), 4.44-4.39(\mathrm{~m}, 1 \mathrm{H}), 4.39-4.35(\mathrm{~m}, 1 \mathrm{H})$, $3.18(\mathrm{t}, J=6.9 \mathrm{~Hz}, 2 \mathrm{H}), 3.08(\mathrm{dd}, J=14.2,7.1 \mathrm{~Hz}, 1 \mathrm{H}), 3.01-2.96(\mathrm{~m}, 1 \mathrm{H}), 2.93(\mathrm{t}, J=7.7$ $\mathrm{Hz}, 2 \mathrm{H}), 1.95-1.72(\mathrm{~m}, 6 \mathrm{H}), 1.72-1.55(\mathrm{~m}, 5 \mathrm{H}), 1.50-1.28(\mathrm{~m}, 4 \mathrm{H})$.

90: ${ }^{1} \mathrm{H}$ NMR $\left(500 \mathrm{MHz}, \mathrm{D}_{2} \mathrm{O}\right) \delta 7.77-7.73(\mathrm{~m}, 2 \mathrm{H}), 7.67-7.64(\mathrm{~m}, 1 \mathrm{H}), 7.59-7.55(\mathrm{~m}$, 1H), $7.42-7.39(\mathrm{~m}, 1 \mathrm{H}), 7.37(\mathrm{dd}, J=9.0,2.3 \mathrm{~Hz}, 2 \mathrm{H}), 7.23-7.20(\mathrm{~m}, 1 \mathrm{H}), 7.08(\mathrm{dd}, J=$ 8.9, 2.2 Hz, 2H), $5.39(\mathrm{~d}, J=4.5 \mathrm{~Hz}, 1 \mathrm{H}), 5.18(\mathrm{~d}, J=3.6 \mathrm{~Hz}, 2 \mathrm{H}), 4.48-4.43(\mathrm{~m}, 1 \mathrm{H}), 4.43$ $-4.39(\mathrm{~m}, 1 \mathrm{H}), 4.37(\mathrm{dd}, J=8.8,6.0 \mathrm{~Hz}, 1 \mathrm{H}), 3.76(\mathrm{t}, J=6.7 \mathrm{~Hz}, 1 \mathrm{H}), 3.17(\mathrm{t}, J=7.0 \mathrm{~Hz}$, 2H), $3.09-2.97(\mathrm{~m}, 2 \mathrm{H}), 2.93(\mathrm{t}, J=7.6 \mathrm{~Hz}, 2 \mathrm{H}), 1.94-1.74(\mathrm{~m}, 6 \mathrm{H}), 1.74-1.57(\mathrm{~m}, 5 \mathrm{H})$, $1.55-1.32(\mathrm{~m}, 4 \mathrm{H})$

91: ${ }^{1} \mathrm{H}$ NMR $\left(500 \mathrm{MHz}, \mathrm{D}_{2} \mathrm{O}\right) \delta 7.96-7.91(\mathrm{~m}, 2 \mathrm{H}), 7.82-7.78(\mathrm{~m}, 2 \mathrm{H}), 7.78-7.74(\mathrm{~m}$, 2H), $7.38(\mathrm{~d}, J=7.9 \mathrm{~Hz}, 2 \mathrm{H}), 7.22-7.20(\mathrm{~m}, 1 \mathrm{H}), 7.07(\mathrm{dd}, J=8.9,3.0 \mathrm{~Hz}, 2 \mathrm{H}), 5.62(\mathrm{~d}, J=$ $9.4 \mathrm{~Hz}, 2 \mathrm{H}), 5.41(\mathrm{~s}, 1 \mathrm{H}), 4.49-4.45(\mathrm{~m}, 1 \mathrm{H}), 4.45-4.40(\mathrm{~m}, 1 \mathrm{H}), 4.40-4.35(\mathrm{~m}, 1 \mathrm{H}), 4.18$ $-4.13(\mathrm{~m}, 1 \mathrm{H}), 3.19(\mathrm{t}, J=6.9 \mathrm{~Hz}, 2 \mathrm{H}), 3.13-3.08(\mathrm{~m}, 1 \mathrm{H}), 3.01-2.96(\mathrm{~m}, 1 \mathrm{H}), 2.92(\mathrm{t}, J=$ $7.7 \mathrm{~Hz}, 2 \mathrm{H}), 2.09(\mathrm{~s}, 1 \mathrm{H}), 1.91-1.76(\mathrm{~m}, 5 \mathrm{H}), 1.72-1.60(\mathrm{~m}, 5 \mathrm{H}), 1.48-1.31(\mathrm{~m}, 4 \mathrm{H}), 1.30$ $-1.25(\mathrm{~m}, 1 \mathrm{H})$.

94: ${ }^{1} \mathrm{H}$ NMR $\left(500 \mathrm{MHz}, \mathrm{D}_{2} \mathrm{O}\right) \delta 7.73(\mathrm{dd}, J=5.3,1.9 \mathrm{~Hz}, 1 \mathrm{H}), 7.47-7.43(\mathrm{~m}, 4 \mathrm{H}), 7.37(\mathrm{dd}$, $J=8.9,2.4 \mathrm{~Hz}, 2 \mathrm{H}), 7.16(\mathrm{~d}, J=5.3 \mathrm{~Hz}, 1 \mathrm{H}), 7.09(\mathrm{~d}, J=8.8 \mathrm{~Hz}, 2 \mathrm{H}), 5.39(\mathrm{~s}, 1 \mathrm{H}), 5.18(\mathrm{~s}$, 2H), $4.54(\mathrm{dd}, J=7.5,6.0 \mathrm{~Hz}, 1 \mathrm{H}), 4.50(\mathrm{t}, J=6.6 \mathrm{~Hz}, 1 \mathrm{H}), 4.47-4.43(\mathrm{~m}, 1 \mathrm{H}), 4.40-4.36$ (m, 1H), $3.15(\mathrm{t}, J=6.8 \mathrm{~Hz}, 2 \mathrm{H}), 3.04-2.99(\mathrm{~m}, 1 \mathrm{H}), 2.94(\mathrm{t}, J=7.7 \mathrm{~Hz}, 2 \mathrm{H}), 1.96-1.77$ $(\mathrm{m}, 6 \mathrm{H}), 1.73-1.60(\mathrm{~m}, 5 \mathrm{H}), 1.50-1.31(\mathrm{~m}, 4 \mathrm{H})$.

97: ${ }^{1} \mathrm{H}$ NMR $\left(500 \mathrm{MHz}, \mathrm{D}_{2} \mathrm{O}\right) \delta 8.04(\mathrm{~s}, 1 \mathrm{H}), 7.78(\mathrm{~d}, J=5.3 \mathrm{~Hz}, 1 \mathrm{H}), 7.52(\mathrm{~d}, J=8.0 \mathrm{~Hz}$, 2H), $7.43(\mathrm{dd}, J=5.2,0.6 \mathrm{~Hz}, 1 \mathrm{H}), 7.42-7.39(\mathrm{~m}, 2 \mathrm{H}), 7.14(\mathrm{~d}, J=8.8 \mathrm{~Hz}, 2 \mathrm{H}), 7.10(\mathrm{~d}, J=$ $8.9 \mathrm{~Hz}, 1 \mathrm{H}), 5.42(\mathrm{~d}, J=4.8 \mathrm{~Hz}, 2 \mathrm{H}), 5.35(\mathrm{~d}, J=5.8 \mathrm{~Hz}, 1 \mathrm{H}), 4.53-4.48(\mathrm{~m}, 1 \mathrm{H}), 4.47-$ $4.44(\mathrm{~m}, 1 \mathrm{H}), 4.39(\mathrm{dd}, J=8.8,6.1 \mathrm{~Hz}, 1 \mathrm{H}), 3.21(\mathrm{t}, J=7.0 \mathrm{~Hz}, 2 \mathrm{H}), 3.17-3.11(\mathrm{~m}, 1 \mathrm{H})$, $3.03-2.97(\mathrm{~m}, 1 \mathrm{H}), 2.94(\mathrm{t}, J=7.7 \mathrm{~Hz}, 2 \mathrm{H}), 1.99-1.77(\mathrm{~m}, 5 \mathrm{H}), 1.75-1.62(\mathrm{~m}, 4 \mathrm{H}), 1.61-$ $1.30(\mathrm{~m}, 5 \mathrm{H})$ 
104: ${ }^{1} \mathrm{H}$ NMR $\left(500 \mathrm{MHz}, \mathrm{D}_{2} \mathrm{O}\right) \delta 7.68-7.66(\mathrm{~m}, 1 \mathrm{H}), 7.50(\mathrm{~d}, J=4.8 \mathrm{~Hz}, 1 \mathrm{H}), 7.44-7.42$ (m, 1H), $7.39(\mathrm{dd}, J=7.9,2.1 \mathrm{~Hz}, 1 \mathrm{H}), 7.36(\mathrm{~d}, J=7.9 \mathrm{~Hz}, 2 \mathrm{H}), 7.34-7.31(\mathrm{~m}, 1 \mathrm{H}), 7.15-$ $7.12(\mathrm{~m}, 1 \mathrm{H}), 7.11-7.05(\mathrm{~m}, 4 \mathrm{H}), 6.99(\mathrm{dd}, J=8.7,2.2 \mathrm{~Hz}, 1 \mathrm{H}), 5.37(\mathrm{~s}, 1 \mathrm{H}), 5.16(\mathrm{~s}, 2 \mathrm{H})$, $4.43(\mathrm{t}, J=7.1 \mathrm{~Hz}, 1 \mathrm{H}), 4.37(\mathrm{dd}, J=8.2,6.1 \mathrm{~Hz}, 1 \mathrm{H}), 3.19(\mathrm{t}, J=6.9 \mathrm{~Hz}, 2 \mathrm{H}), 2.94(\mathrm{t}, J=$ $7.7 \mathrm{~Hz}, 2 \mathrm{H}), 1.97-1.75(\mathrm{~m}, 6 \mathrm{H}), 1.75-1.62(\mathrm{~m}, 5 \mathrm{H}), 1.52-1.30(\mathrm{~m}, 5 \mathrm{H}), 1.26(\mathrm{~s}, 1 \mathrm{H})$. 


\section{${ }^{1} \mathrm{H}$ and ${ }^{13} \mathrm{C}$ NMR spectra}

Compound 1, ${ }^{1} \mathrm{H}$ NMR (300 MHz, acetone- $\left.d_{6}\right)$<smiles>O=C(NC(C(=O)O)c1ccc(O)cc1)OCC1c2ccccc2-c2ccccc21</smiles>

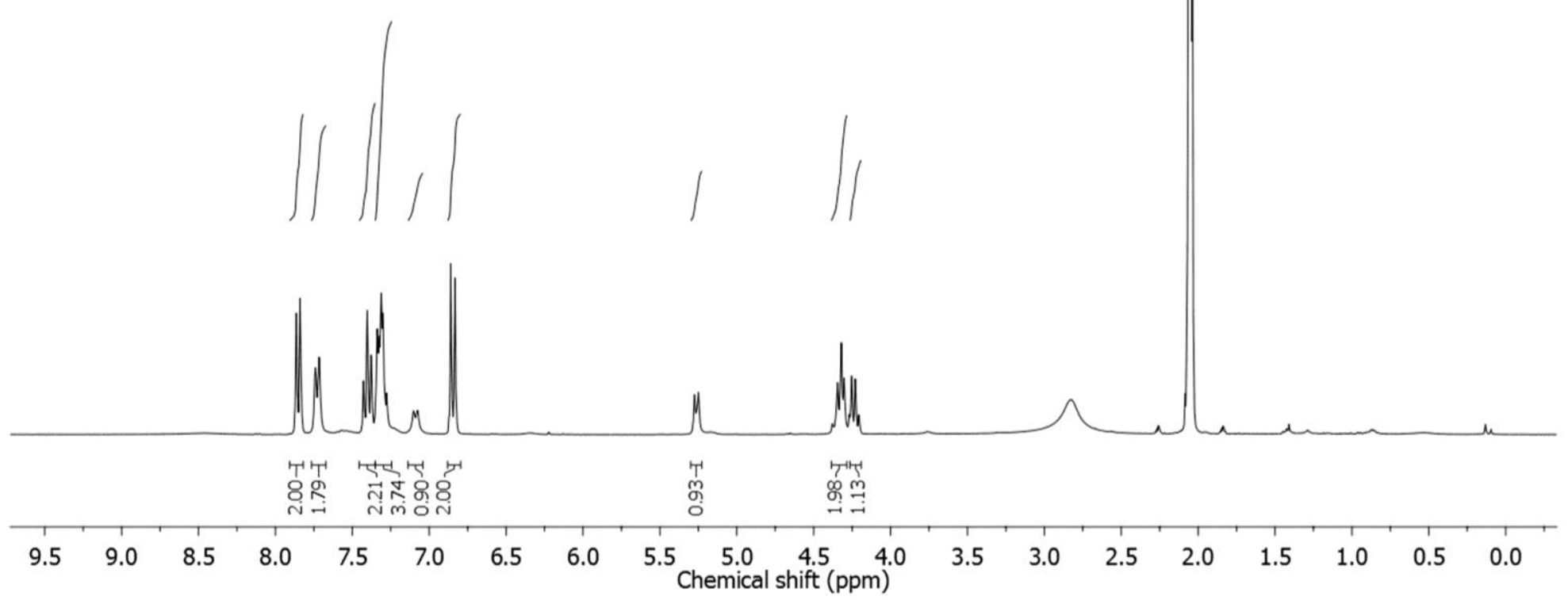


Compound 2, ${ }^{1} \mathrm{H}$ NMR (300 MHz, acetone- $d_{6}$ )
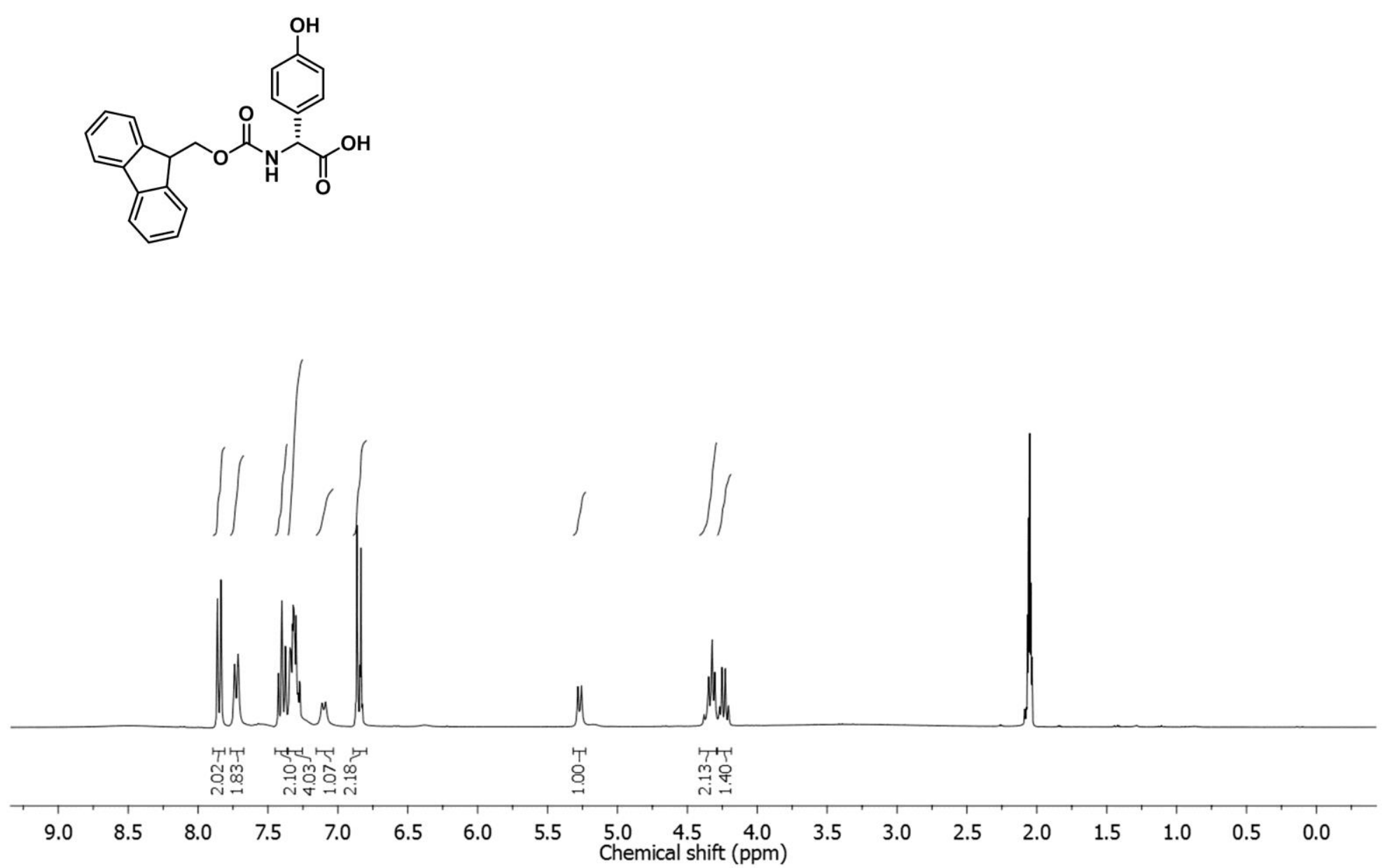
Compound $2,{ }^{13} \mathrm{C}$ NMR (100 MHz, acetone- $d_{6}$ )
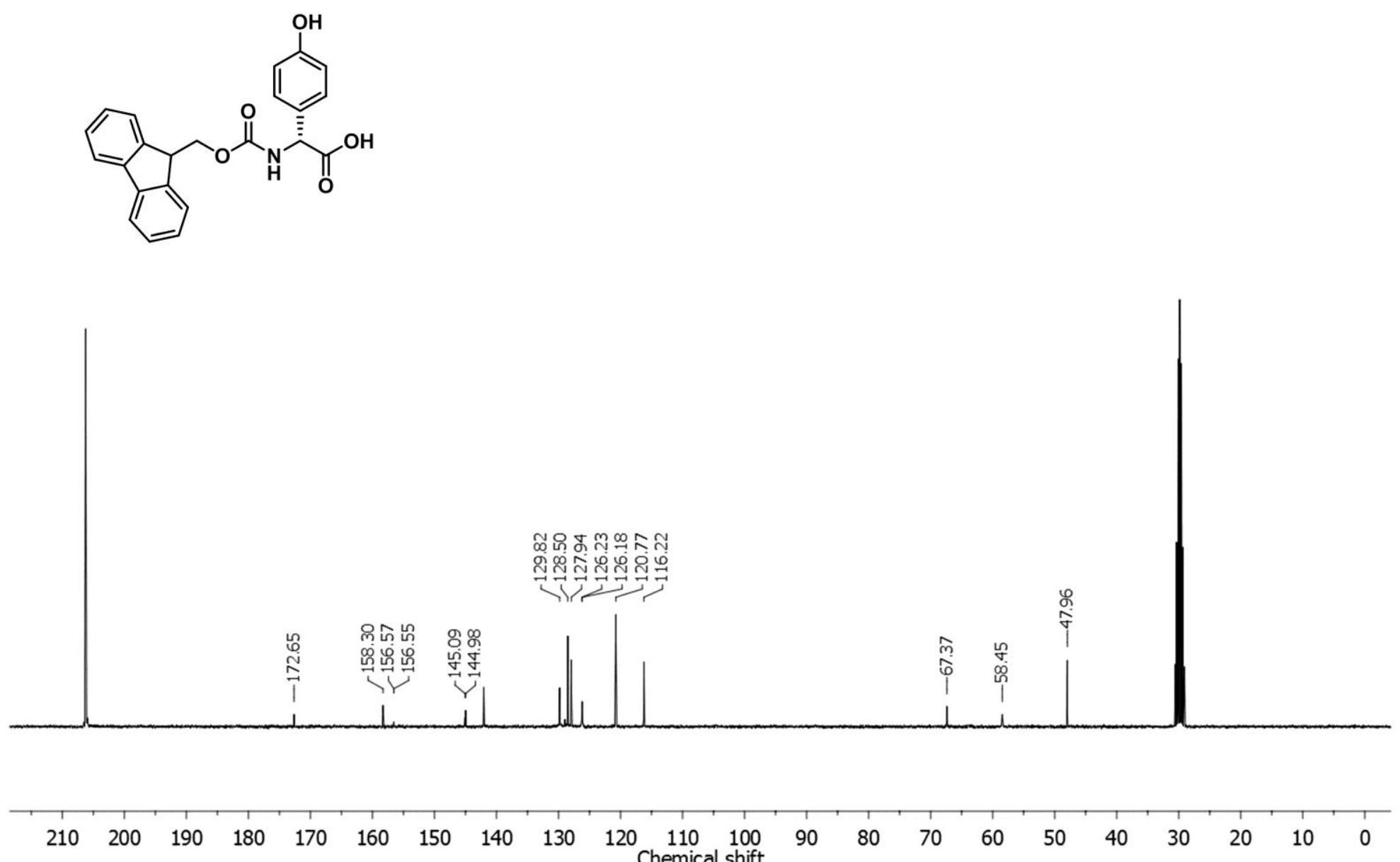
Compound 3a, ${ }^{1} \mathrm{H}$ NMR (300 MHz, DMSO- $\left.d_{6} / \mathrm{NaOD}\right)$
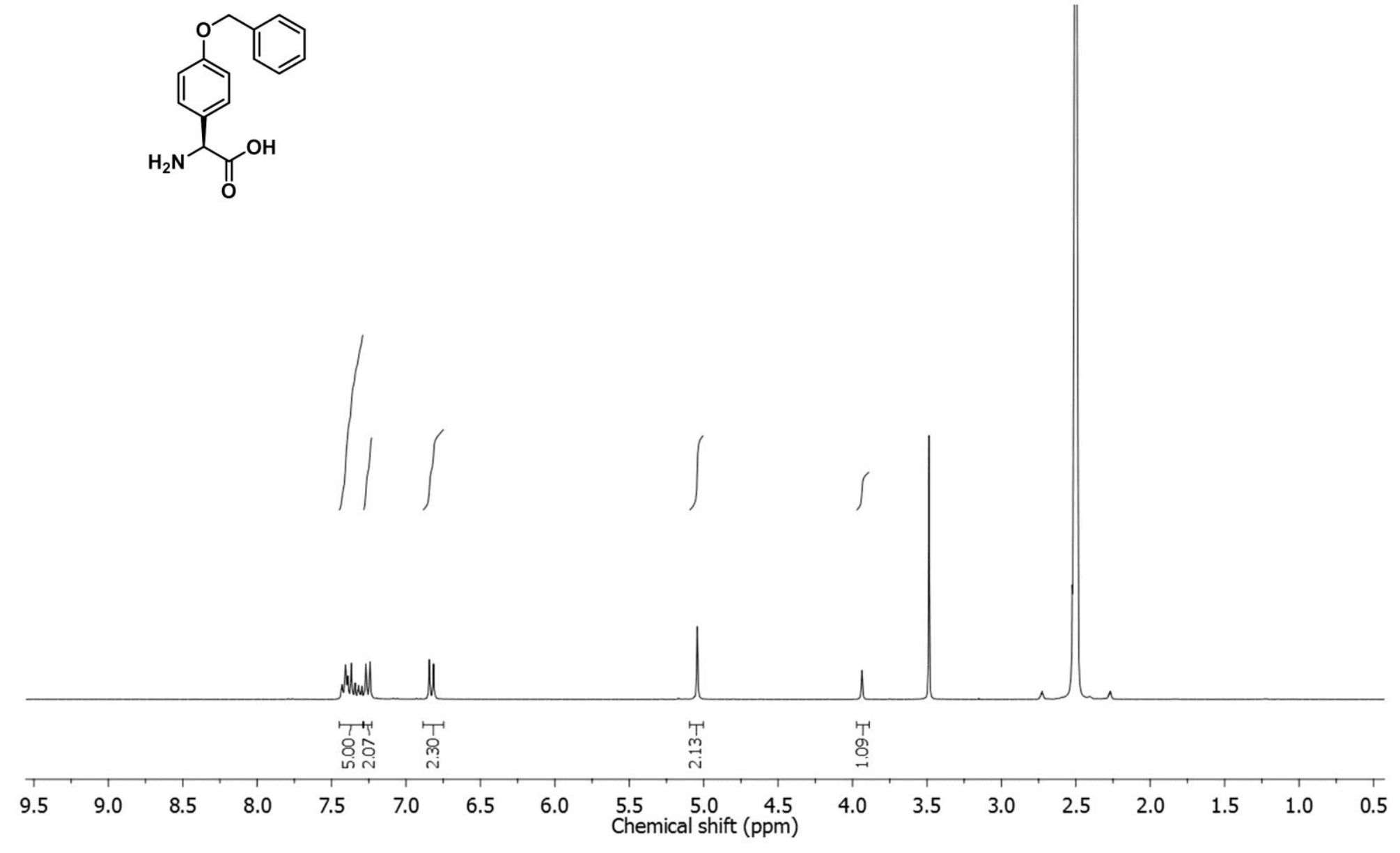
Compound 3a, ${ }^{13} \mathrm{C}$ NMR (APT, $75 \mathrm{MHz}$, DMSO- $d_{6} / \mathrm{NaOD}$ )
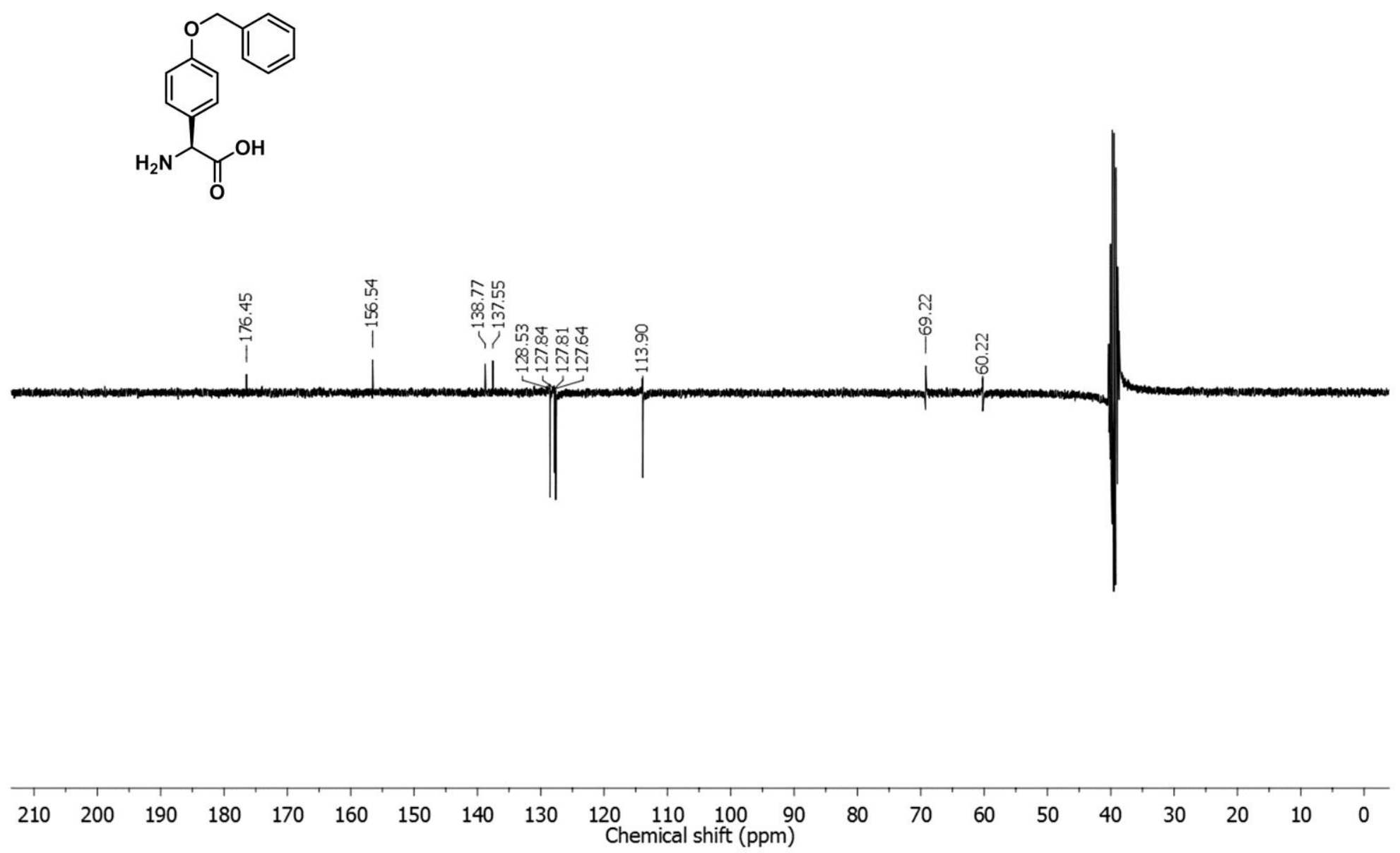
Compound 4a, ${ }^{1} \mathrm{H}$ NMR (300 MHz, $\left.\mathrm{D}_{2} \mathrm{O} / \mathrm{NaOD}\right)$
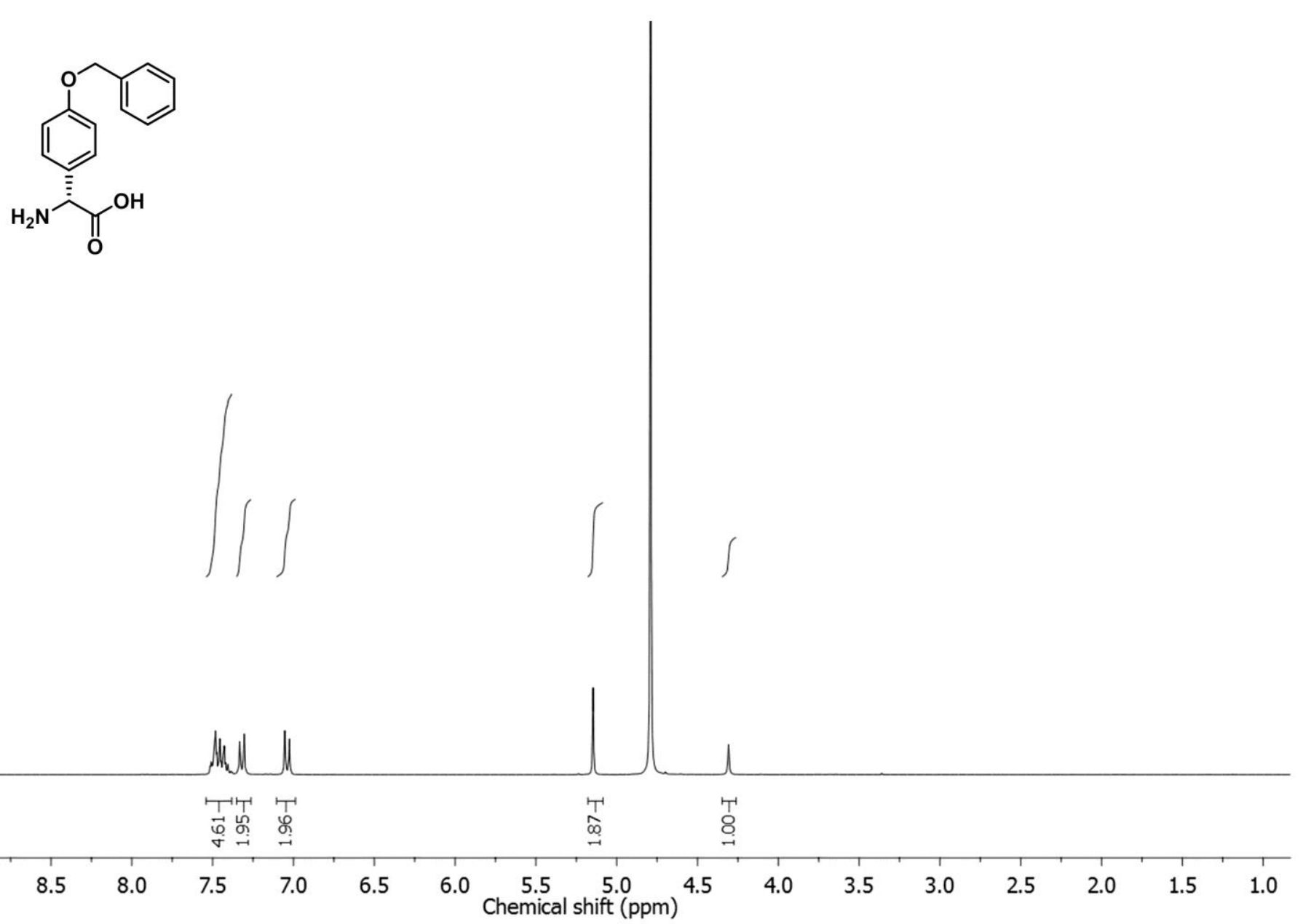
Compound 7a, ${ }^{1} \mathrm{H}$ NMR (300 MHz, DMSO- $\left.d_{6} / \mathrm{NaOD}\right)$
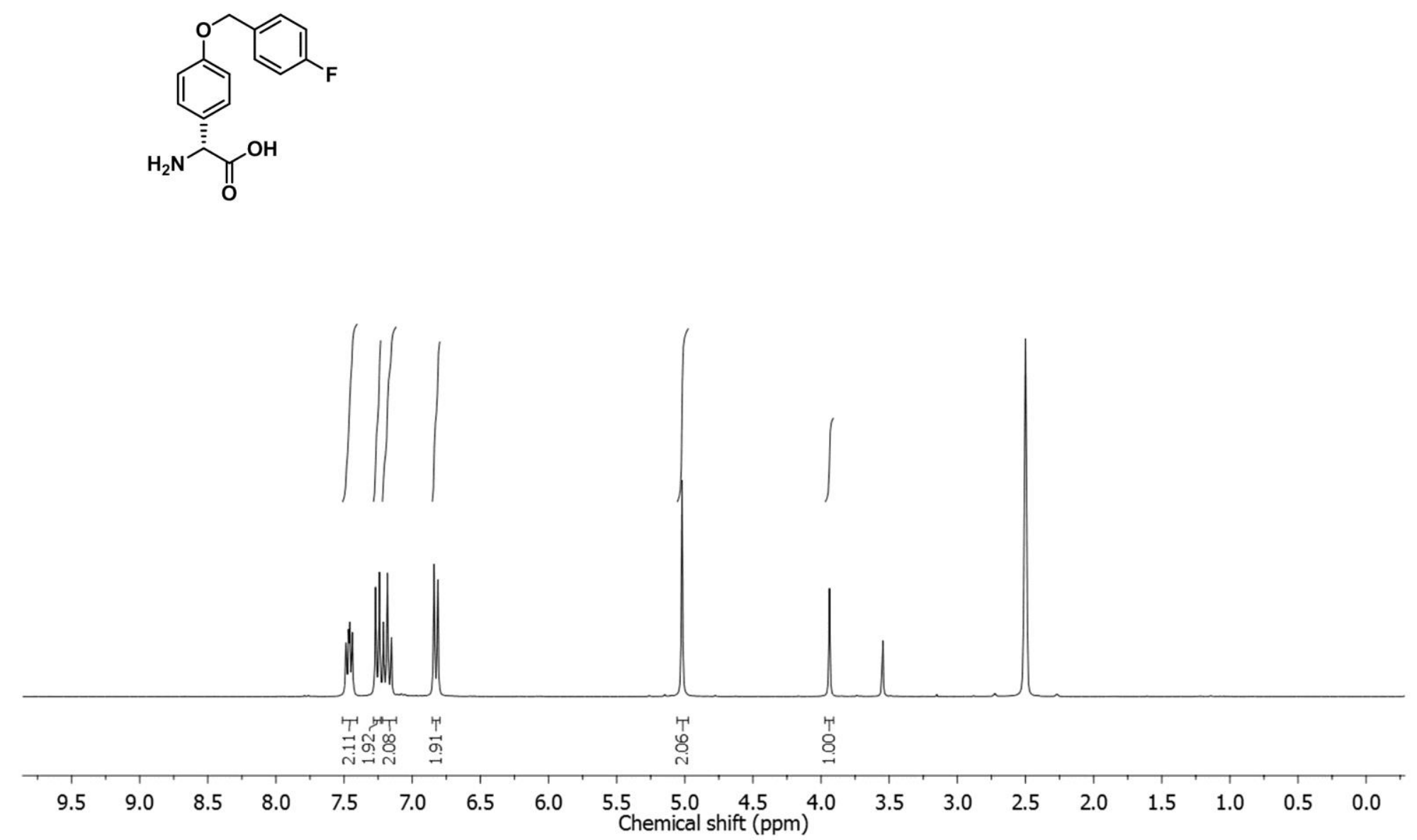
Compound 9a, ${ }^{1} \mathrm{H}$ NMR (300 MHz, DMSO- $\left.d_{6} / \mathrm{NaOD}\right)$
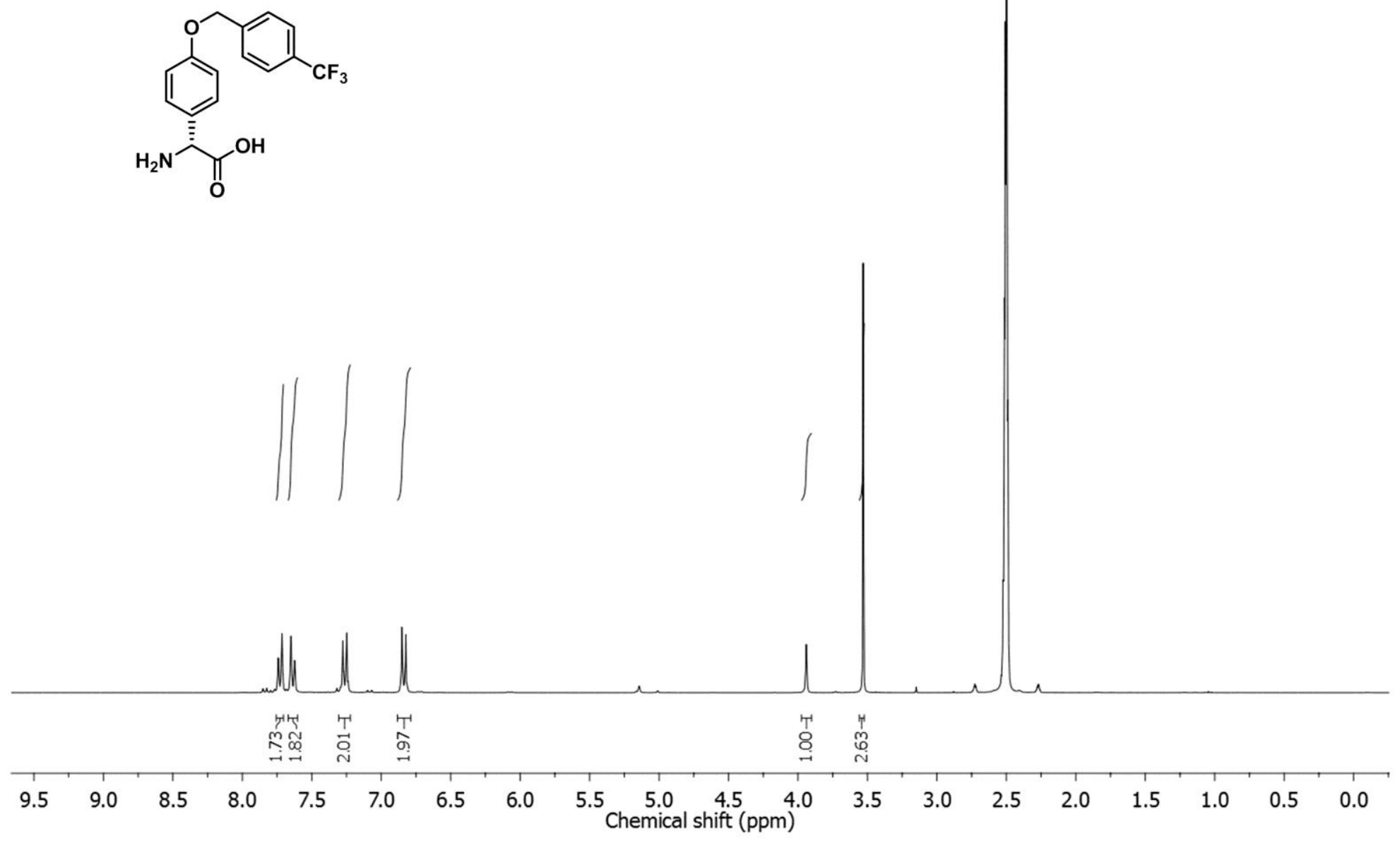
Compound 11a, ${ }^{1} \mathrm{H}$ NMR (300 MHz, DMSO- $\left.d_{6} / \mathrm{NaOD}\right)$
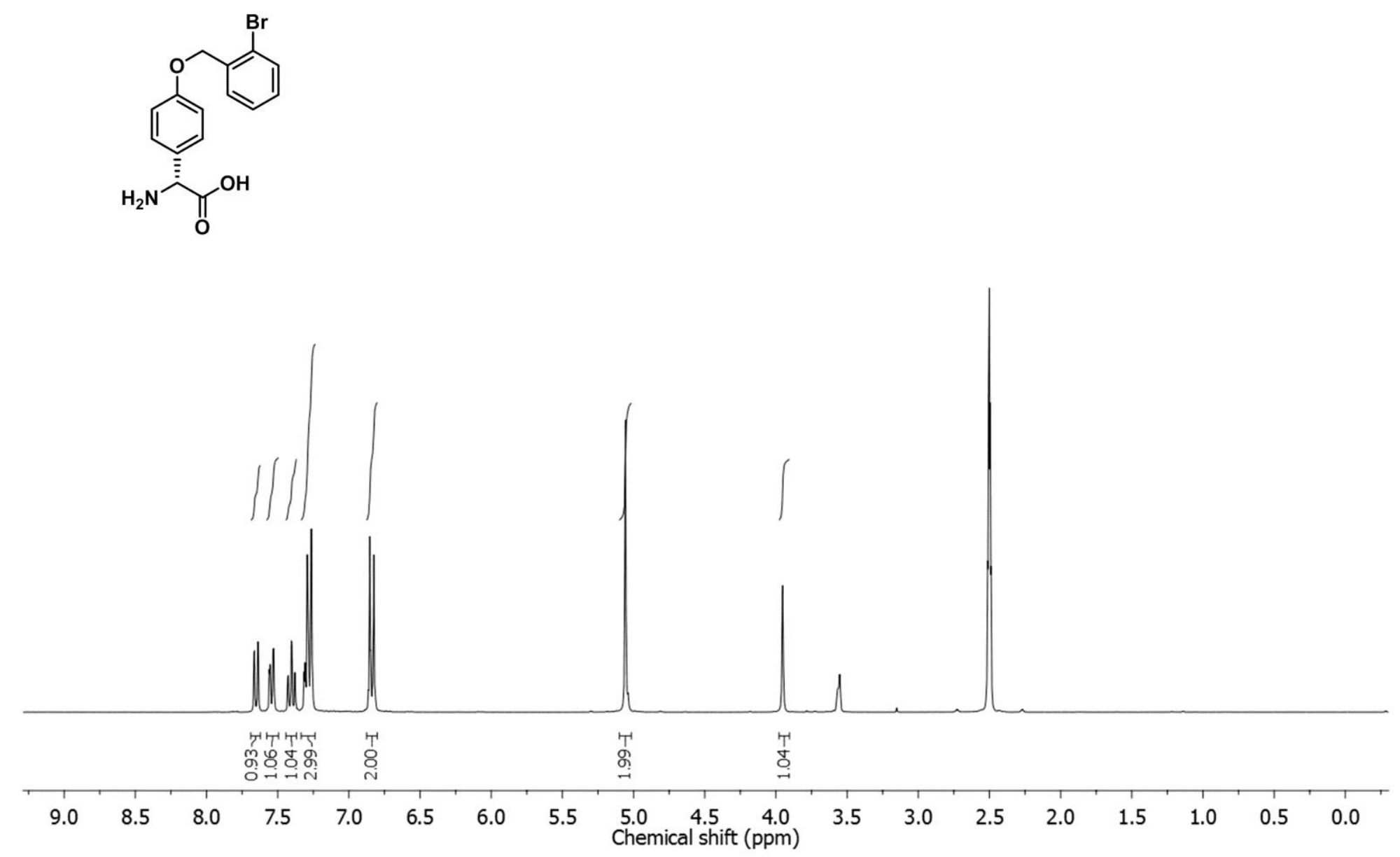
Compound 14a, ${ }^{1} \mathrm{H}$ NMR (300 MHz, DMSO- $d_{6} / \mathrm{NaOD}$ )
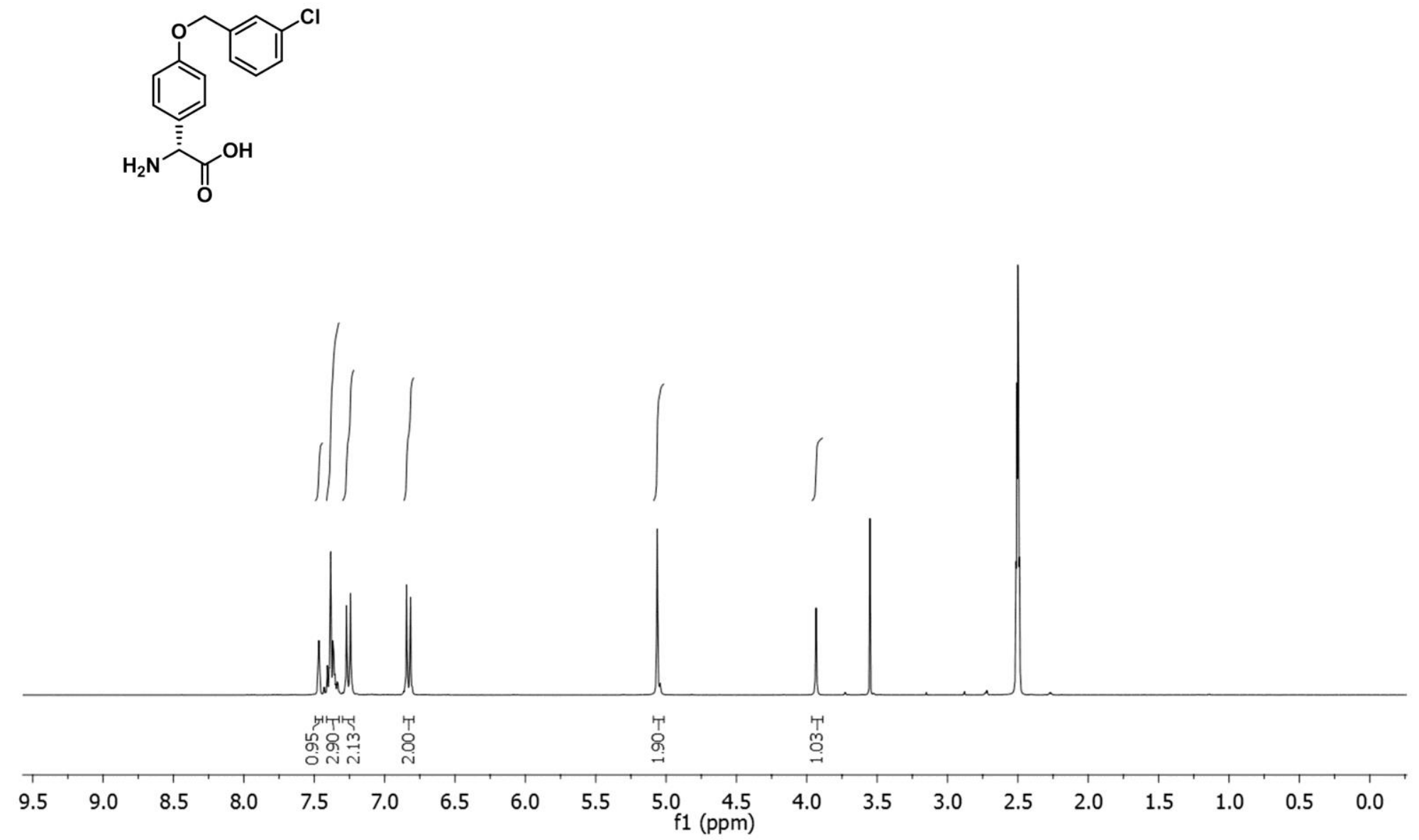
Compound 18a, ${ }^{1} \mathrm{H}$ NMR (300 MHz, DMSO- $d_{6} / \mathrm{NaOD}$ )

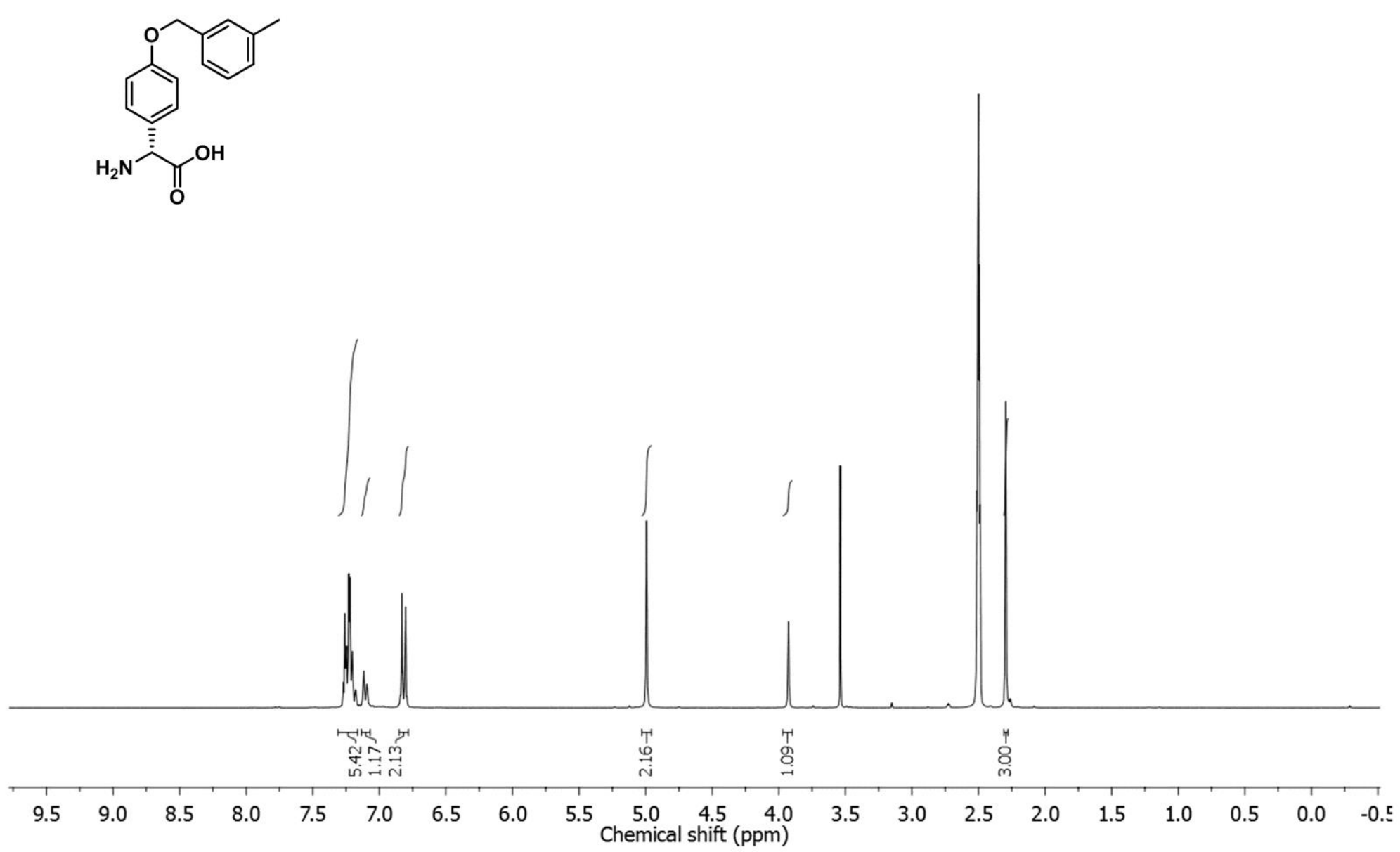


Compound 19a, ${ }^{1} \mathrm{H}$ NMR (300 MHz, DMSO- $d_{6} / \mathrm{NaOD}$ )
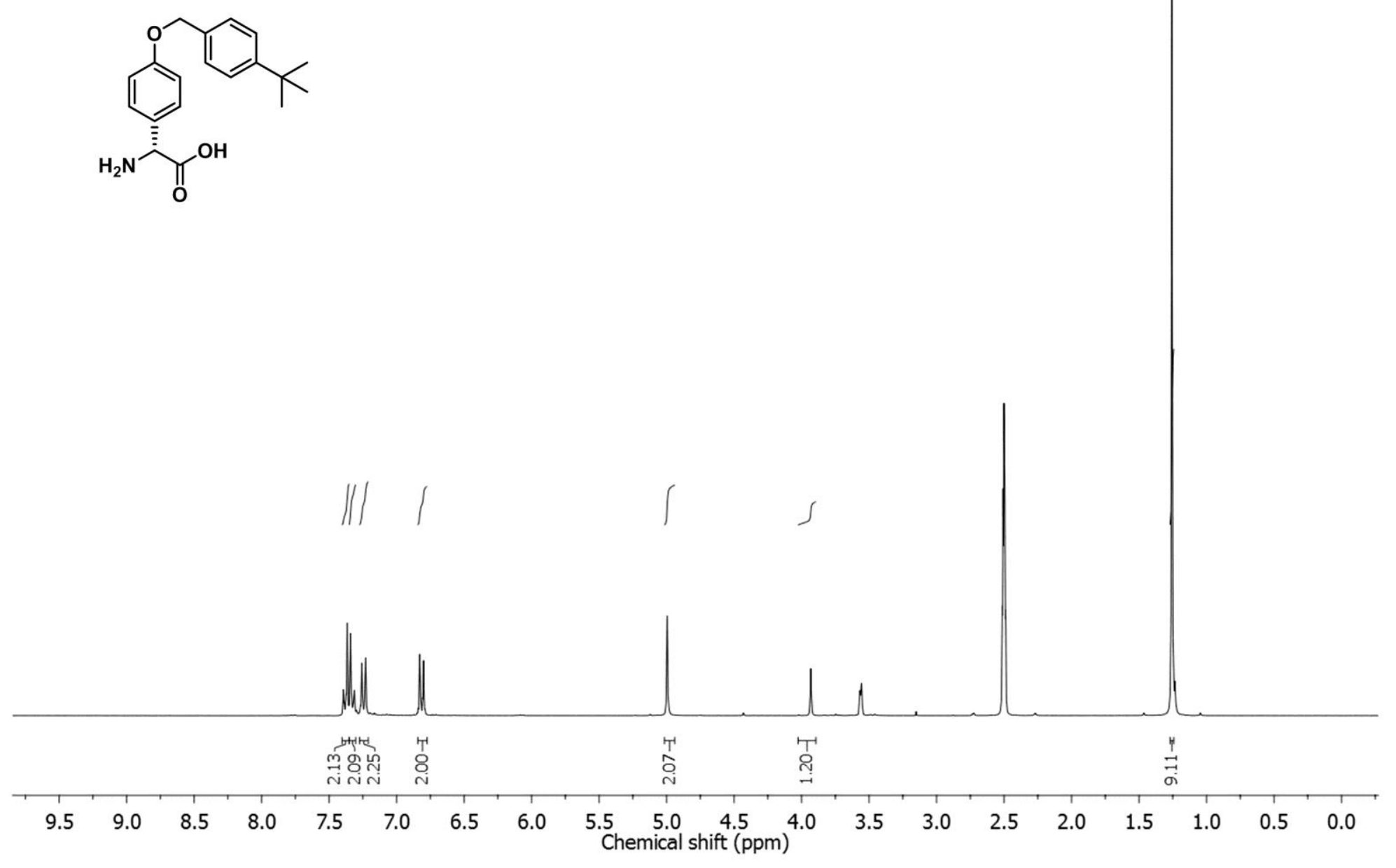
Compound 20a, ${ }^{1} \mathrm{H}$ NMR (300 MHz, DMSO- $d_{6} / \mathrm{NaOD}$ )
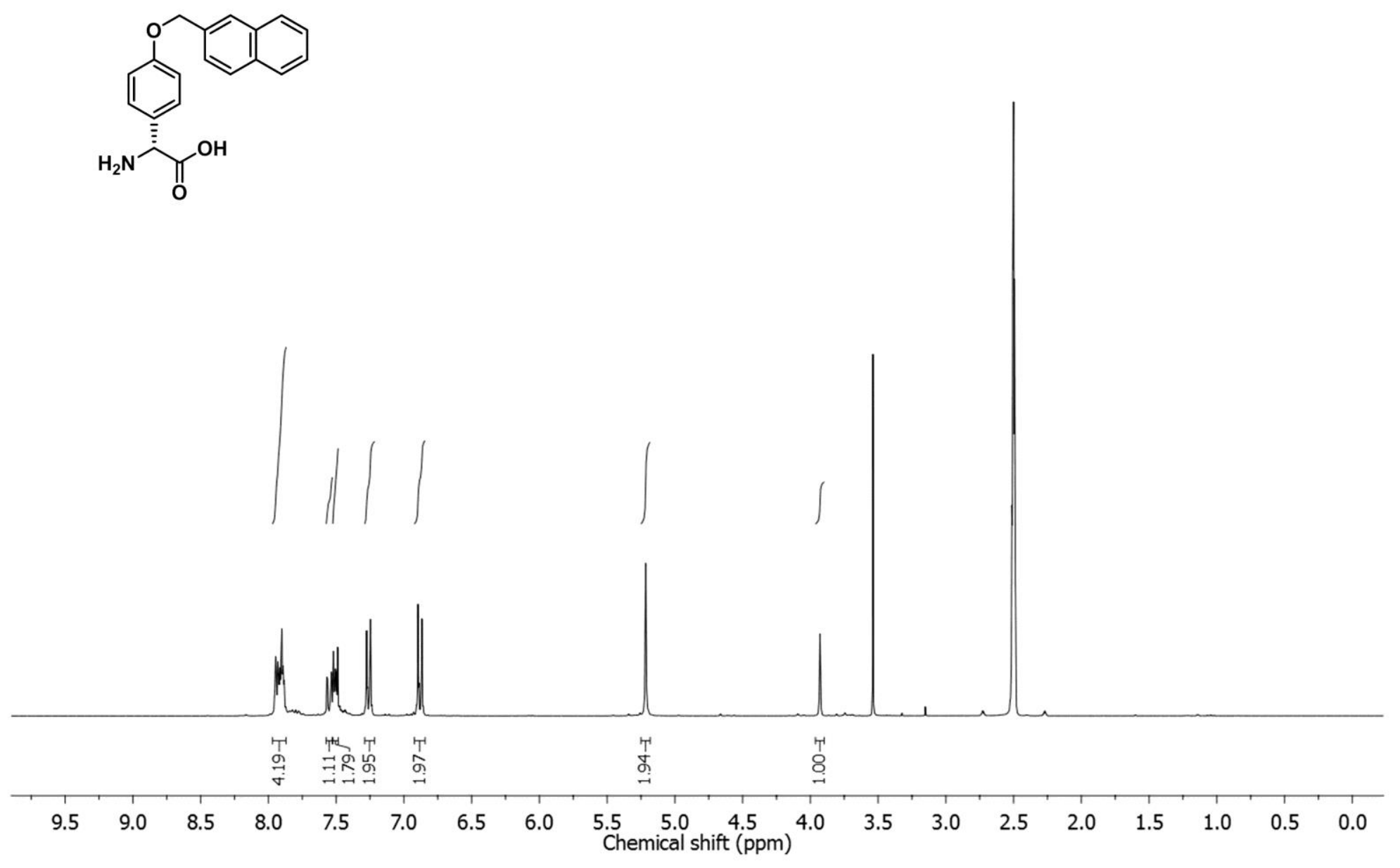
Compound 24, ${ }^{1} \mathrm{H}$ NMR $\left(500 \mathrm{MHz}, \mathrm{D}_{2} \mathrm{O}\right)$

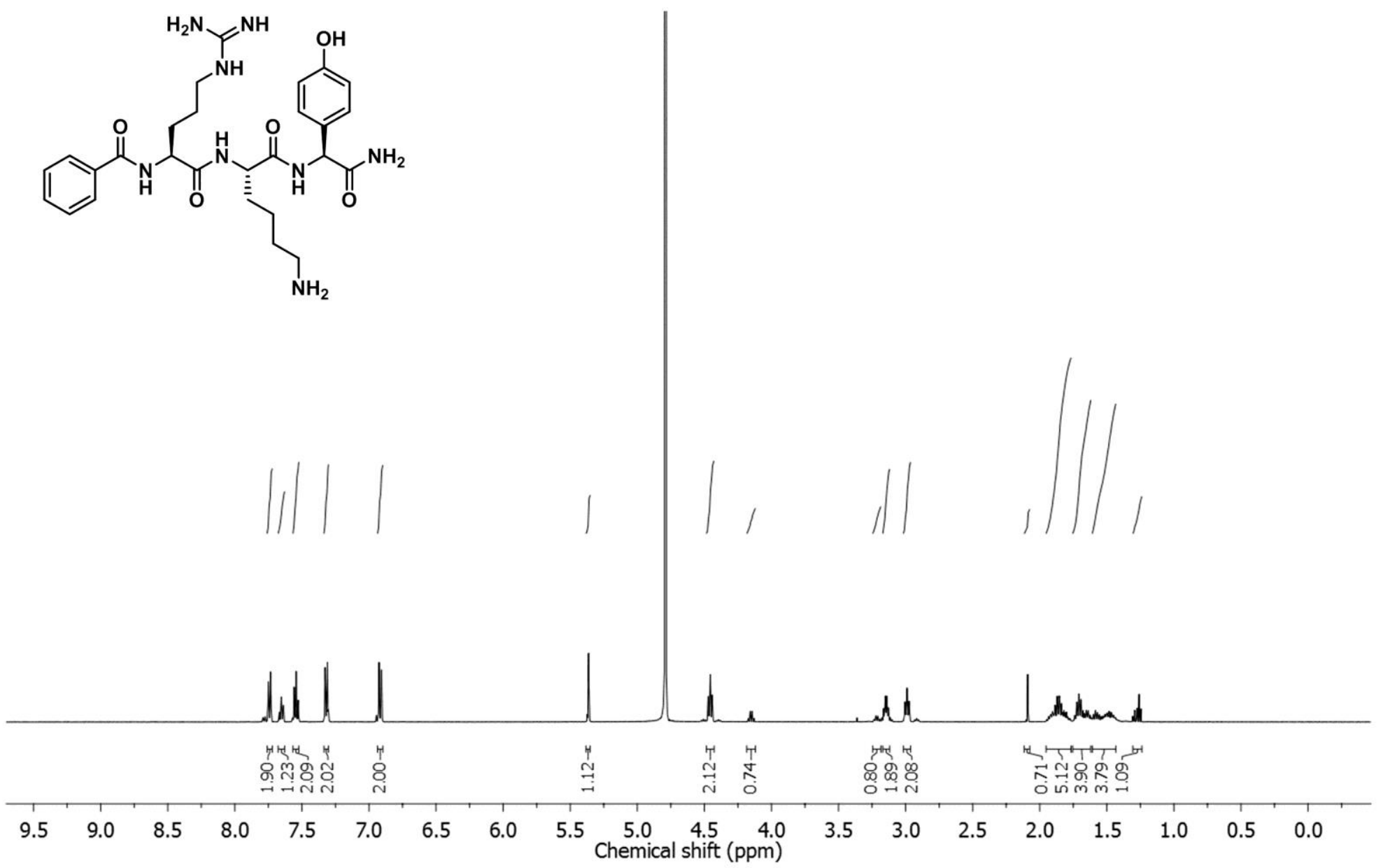


Compound 27, ${ }^{1} \mathrm{H}$ NMR $\left(500 \mathrm{MHz}, \mathrm{CD}_{3} \mathrm{OD}\right)$

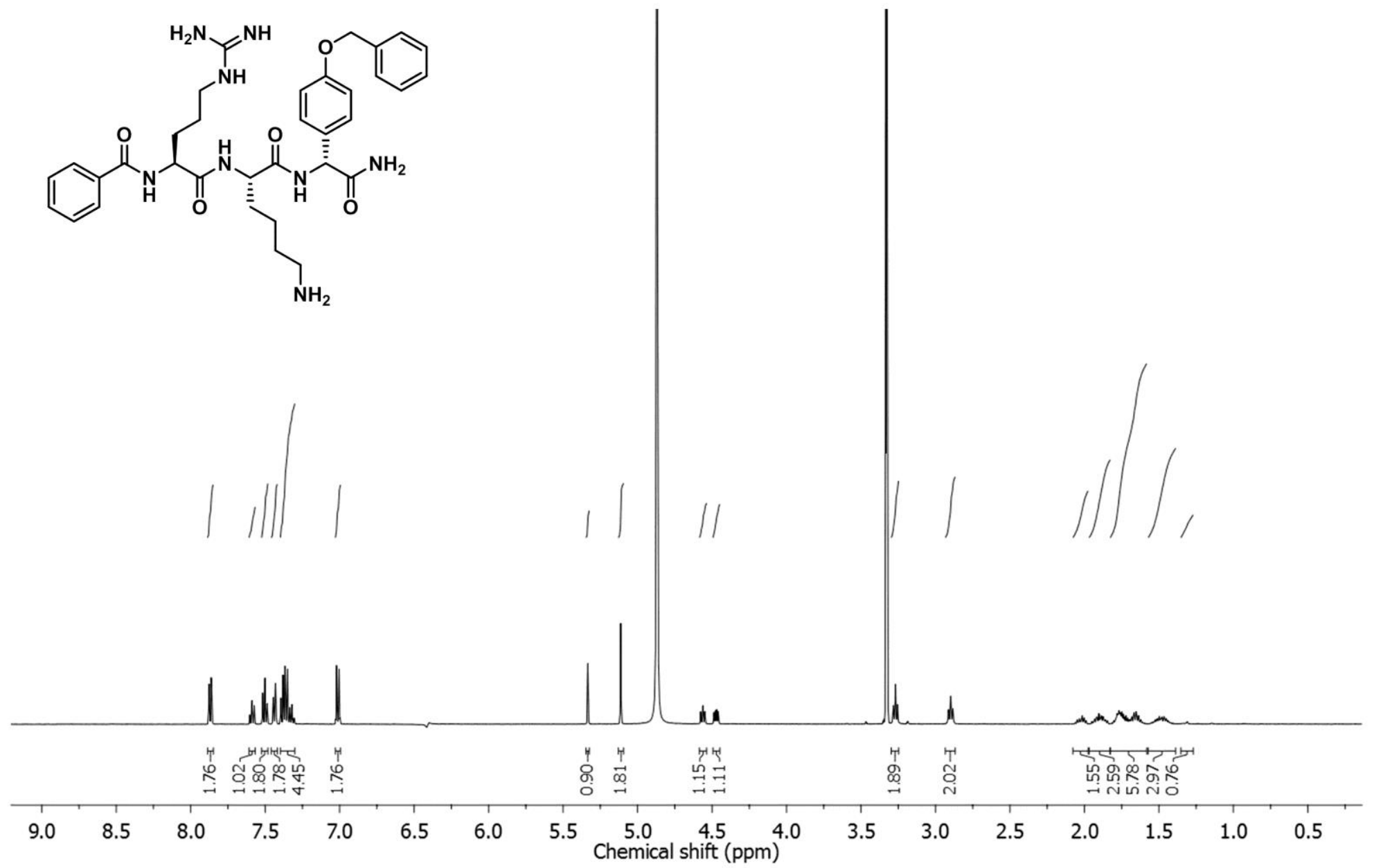


Compound 27, ${ }^{13} \mathrm{C}$ NMR (APT, $\left.126 \mathrm{MHz}, \mathrm{CD}_{3} \mathrm{OD}\right)$
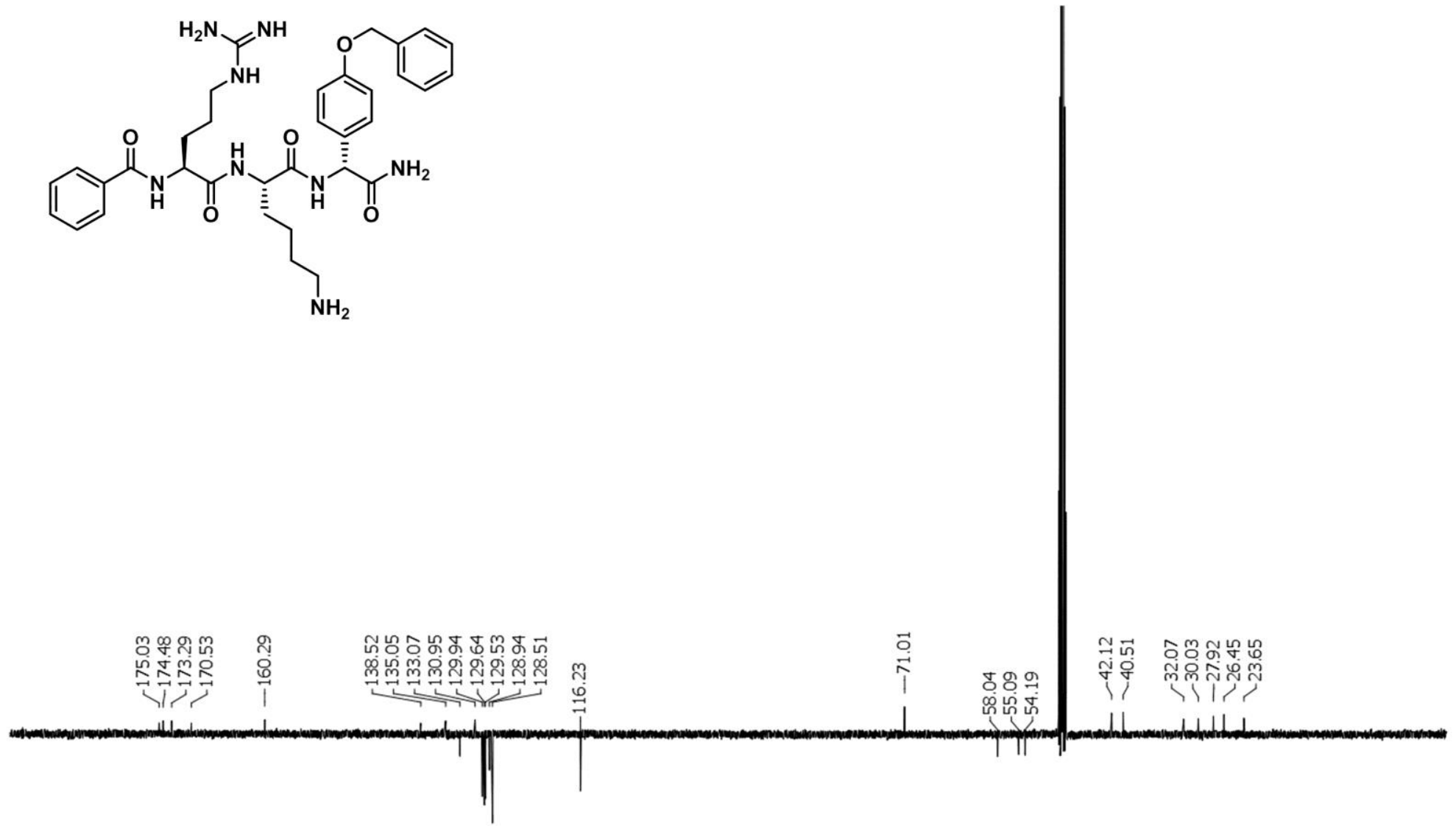

$\begin{array}{lllllllllllllllll}190 & 180 & 170 & 160 & 150 & 140 & 130 & 120 & \begin{array}{c}110 \\ \text { Chemical shift (ppm) }\end{array} 100 & 70 & 60 & 50 & 40 & 30 & 20 & 10 & 0\end{array}$ 
Compound 83, ${ }^{1} \mathrm{H}$ NMR $\left(500 \mathrm{MHz}, \mathrm{D}_{2} \mathrm{O}\right)$

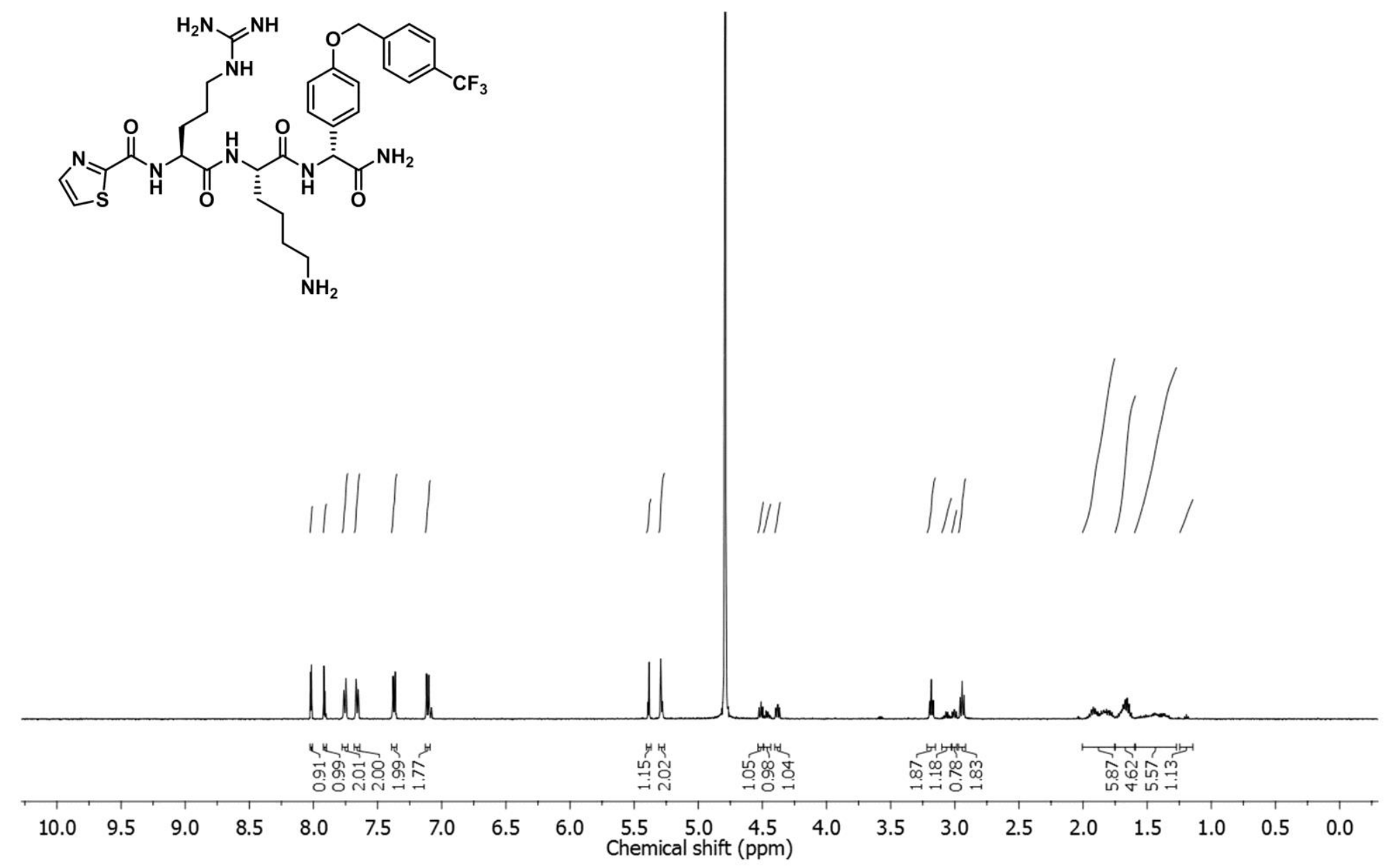


Compound 86, ${ }^{1} \mathrm{H}$ NMR $\left(500 \mathrm{MHz}, \mathrm{D}_{2} \mathrm{O}\right)$

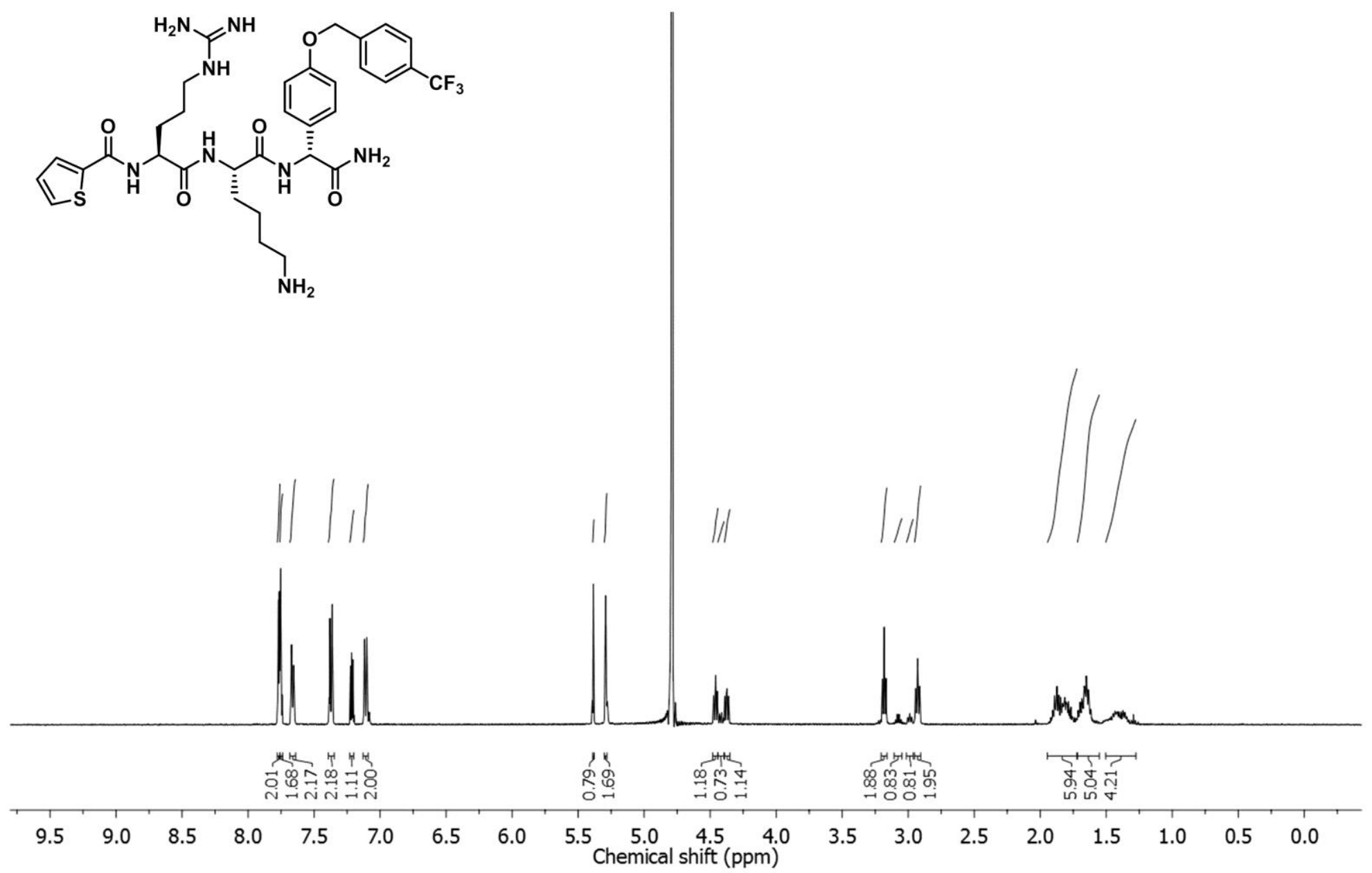


Compound 90, ${ }^{1} \mathrm{H}$ NMR $\left(500 \mathrm{MHz}, \mathrm{D}_{2} \mathrm{O}\right)$

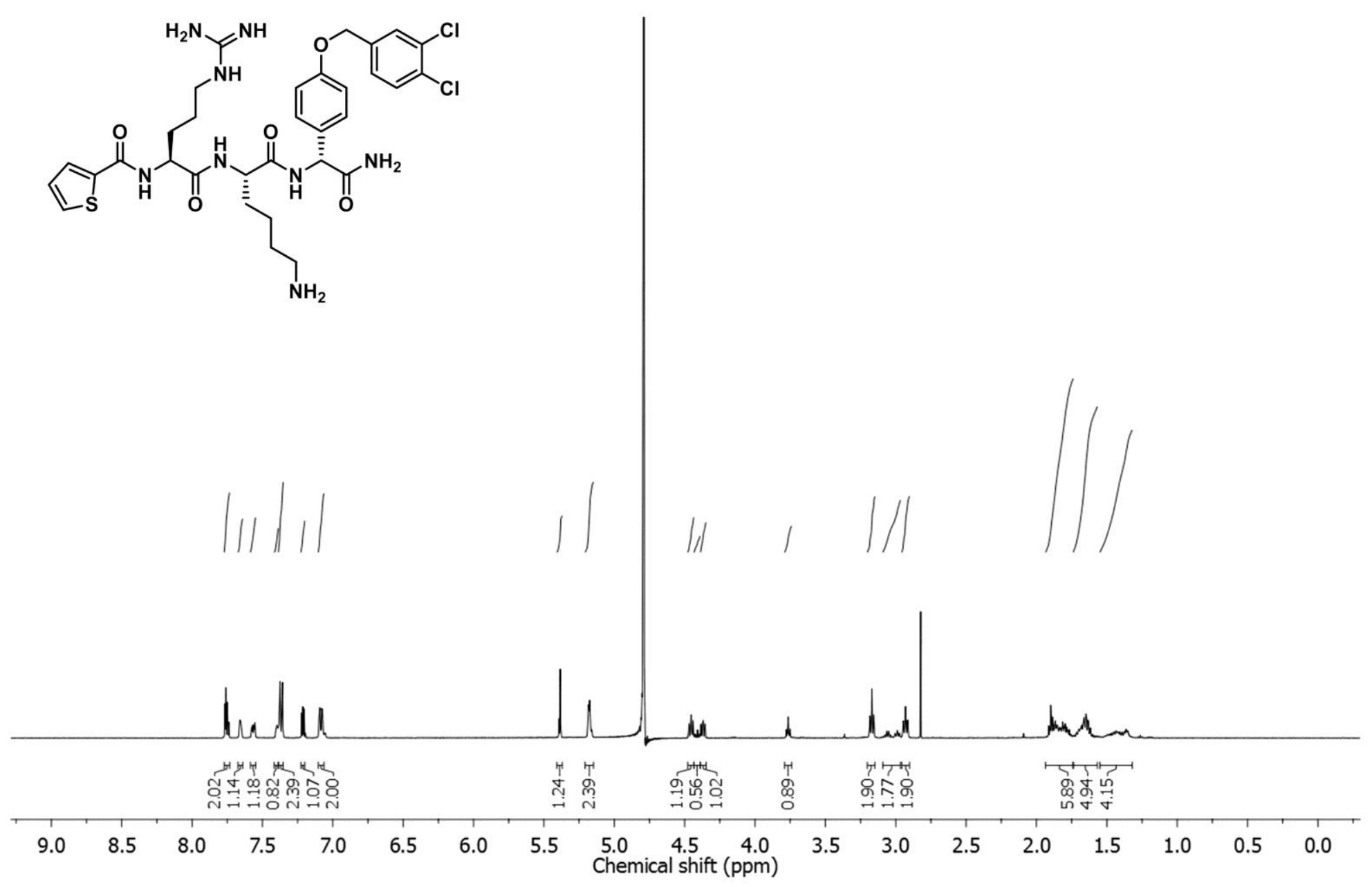




\section{Compound 91, ${ }^{1} \mathrm{H}$ NMR (500 MHz, $\mathrm{D}_{2} \mathrm{O}$ )}
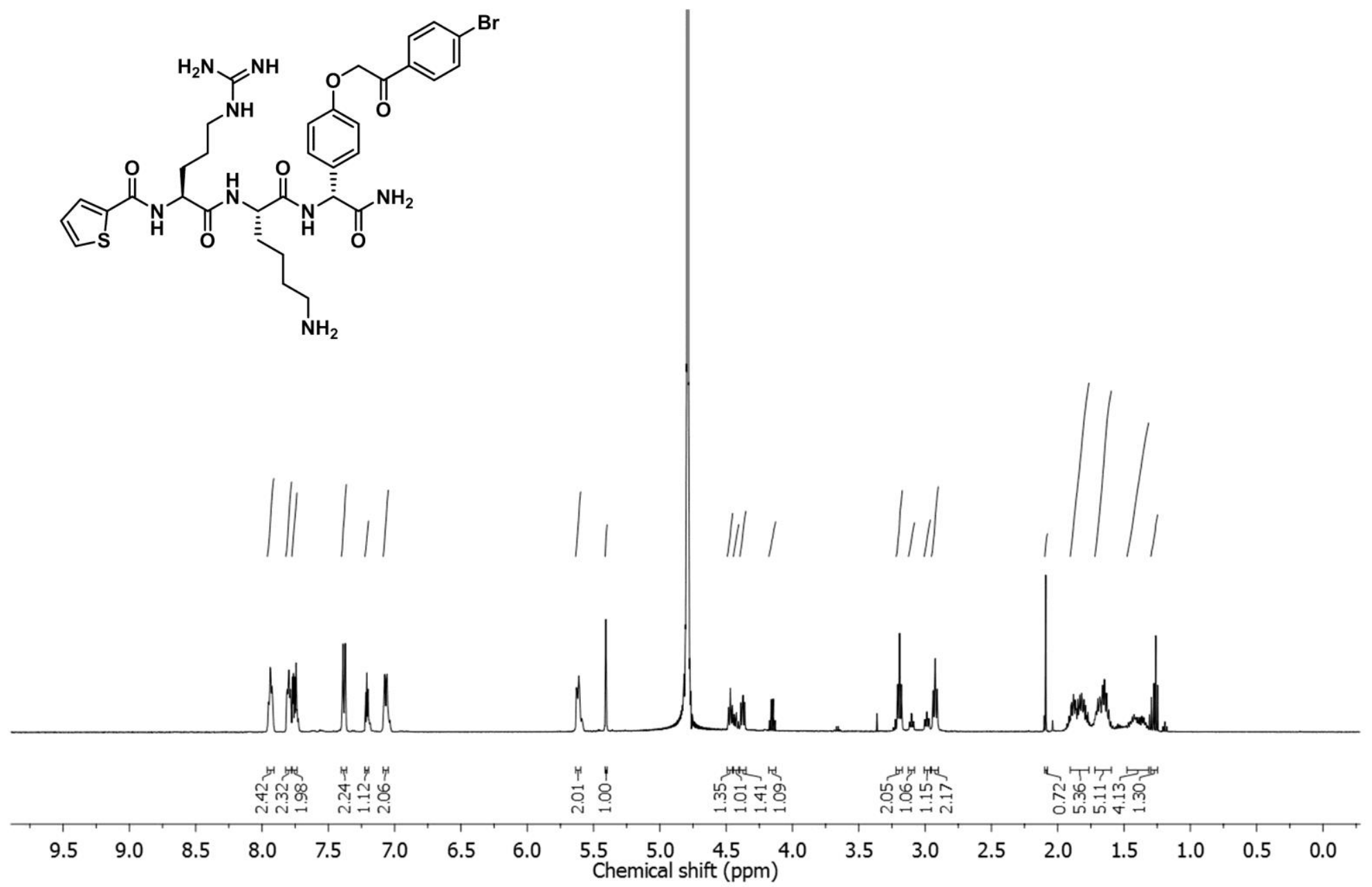
Compound 104, ${ }^{1} \mathrm{H}$ NMR $\left(500 \mathrm{MHz}, \mathrm{D}_{2} \mathrm{O}\right)$
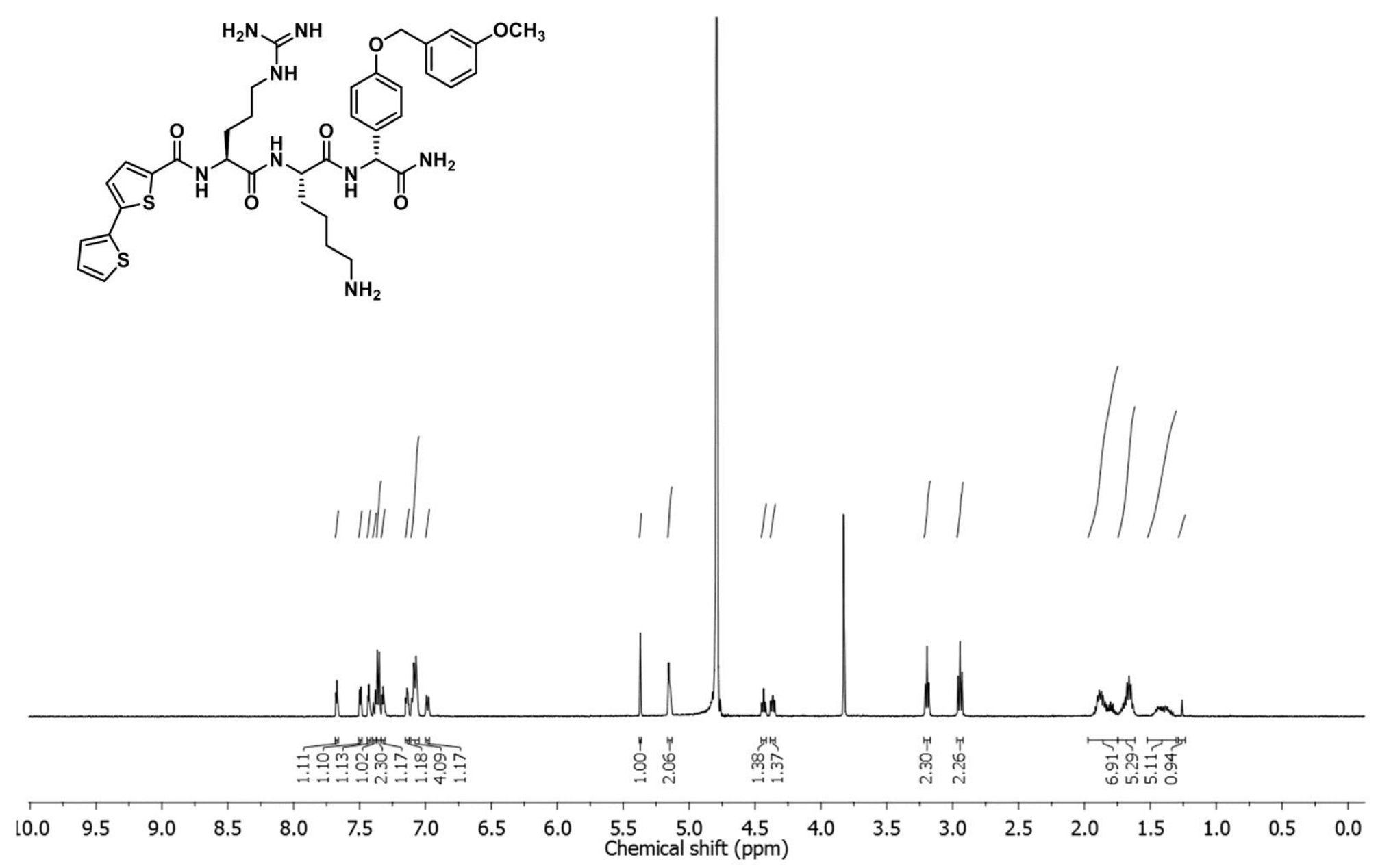


\section{References}

1. Derible, A.; Diebold, C.; Dentzer, J.; Gadiou, R.; Becht, J.-M.; Le Drian, C., A Palladium Catalyst Supported on Carbon-Coated Cobalt Nanoparticles - Preparation of Palladium-Free Biaryls by Suzuki-Miyaura Reactions in Ethanol. Eur. J. Org. Chem. 2014, 2014 (34), 7699-7706.

2. Swinnen, D.; Morandi, F. Alpha-Amino Boronic Acid Derivatives, Selective Immunoproteasome Inhibitors. WO2013092979 A1, June 27, 2013.

3. Nitsche, C.; Schreier, V. N.; Behnam, M. A. M.; Kumar, A.; Bartenschlager, R.; Klein, C. D., Thiazolidinone-Peptide Hybrids as Dengue Virus Protease Inhibitors with Antiviral Activity in Cell Culture. J. Med. Chem. 2013, 56 (21), 8389-8403.

4. Weigel, L. F.; Nitsche, C.; Graf, D.; Bartenschlager, R.; Klein, C. D., Phenylalanine and Phenylglycine Analogs as Arginine Mimetics in Dengue Protease Inhibitors. J. Med. Chem. 2015, 58 (19), 7719-7733.

5. Bodenreider, C.; Beer, D.; Keller, T. H.; Sonntag, S.; Wen, D.; Yap, L.; Yau, Y. H.; Shochat, S. G.; Huang, D.; Zhou, T.; Caflisch, A.; Su, X.-C.; Ozawa, K.; Otting, G.; Vasudevan, S. G.; Lescar, J.; Lim, S. P., A Fluorescence Quenching Assay to Discriminate between Specific and Nonspecific Inhibitors of Dengue Virus Protease. Anal. Biochem. 2009, 395 (2), 195-204.

6. Behnam, M. A. M.; Nitsche, C.; Vechi, S. M.; Klein, C. D., C-Terminal Residue Optimization and Fragment Merging: Discovery of a Potent Peptide-Hybrid Inhibitor of Dengue Protease. ACS Med. Chem. Lett. 2014, 5 (9), 1037-1042. 